\title{
Design Optimization of Dump Diffusers with NACA 66-021 Shaped Flame Tube
}

\author{
Aravind S, ${ }^{1}$ Sabarinathan $\mathrm{G},{ }^{2}$ Dhinakaran $\mathrm{S},{ }^{3}$ \\ Sanjay Kumar S, ${ }^{4}$ and Sundararaj $\mathrm{K}^{5}$ \\ Kumaraguru College of Technology, Coimbatore - 641 049, Tamil Nadu, India \\ V.R. Sanal Kumar 6 \\ Indian Space Research Organization, Trivandrum - 695022, Kerala, India
}

\begin{abstract}
Although the design and optimization of an aircraft engine have been advanced significantly over the last few decades, an aerodynamic shape optimization of dump diffuser is still an active research topic in the modern aircraft industry aiming for achieving more efficient combustion and the less total pressure losses. In our previous connected paper (AIAA 2019-4258) we reported that the dump diffuser facilitated by multiple-steps pre-diffuser cones, along with the aerodynamically-shaped adjustable flame tube that could improve the performance characteristics of aero gas turbine engines under a wide range of operating conditions. Herein, we attempted the aerodynamic design optimization of dump diffusers with NACA 66-021 shaped flame tube for improving the static pressure recovery. Numerical studies have been carried out using a validated 2D density-based steady viscous flow solver with the standard $k$ - $\varepsilon$ turbulence model. The code is verified and validated using the exact value of the boundary layer displacement thickness predicted at the Sanal flow choking condition. Parametric studies reveal that a dump diffuser with the NACA 66-021 airfoil-shaped flame tube has an improved static pressure recovery than the previously proposed NACA 0012 shaped flame tube. We observed that, in addition to the fluid dynamics and the geometric variables of a dump-diffuser, the thickness-to-chord ratio of the NACA airfoil-shaped flame tube is also having a bearing on the static pressure recovery. We concluded that the aerodynamics design optimization of dump diffusers with the NACA series airfoil-shaped flame tube is a meaningful objective for negating the large total pressure losses lucratively for an efficient combustion.
\end{abstract}

\section{Nomenclature}

$A=$ area of cross-section

$A_{2} / A_{1} \quad=$ area ratio

$B \quad=$ blockage factor

$C_{p} \quad=$ pressure coefficient

$c \quad=$ chord

$d=$ distance between the pre-diffuser exit and the flame dome

$L=$ total length of the dump diffuser

$P \quad=$ static pressure

Po $\quad=$ total pressure

$\mathrm{Tu} \quad=$ turbulence intensity

\footnotetext{
${ }^{1}$ Undergraduate Student, Dept. of Aeronautical Engineering; 12aravindarthi@ gmail.com

${ }^{2}$ Undergraduate Student, Dept. of Aeronautical Engineering; sabarinathan1.16ae@kct.ac.in

${ }^{3}$ Undergraduate Student, Dept. of Aeronautical Engineering; dhinakaran.16ae@kct.ac.in

${ }^{4}$ Undergraduate Student, Dept. of Aeronautical Engineering; sanjaykumar.16ae@kct.ac.in

${ }^{5}$ Professor and Head, Dept. of Aeronautical Engineering, sundararaj.k.aeu@kct.ac.in

${ }^{6}$ Professor of Aeronautics (KCT) and Aerospace Scientist (ISRO - SC No.6301/2013), and Project Coordinator, Indo-Russian Joint Research Project at the Indian Institute of Science, Bangalore-12, Senior AIAA Member; vr_sanalkumar@yahoo.co.in
} 


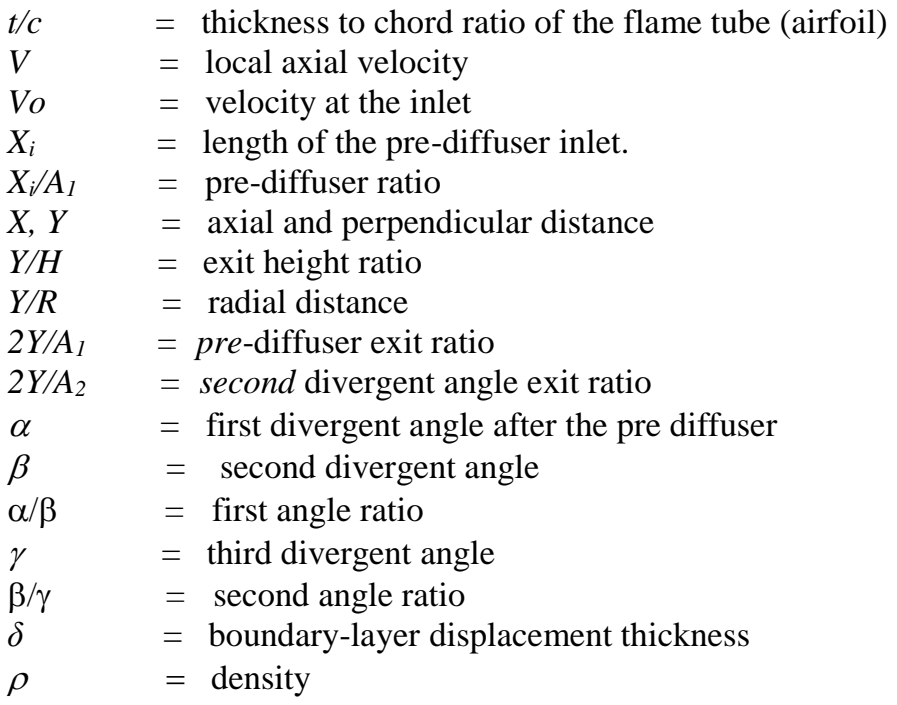

\section{Introduction}

A dump diffuser is a type of combustor diffuser. The diffuser is one of the key components of the gas turbine combustor. Its primary function is to slow down the airflow delivered by the compressor to promote an efficient combustion and avoid the large total pressure losses. Of late many experimental and numerical studies have been reported on diffuser flows with remarkable physical insight on critical flow features. Nonetheless, the design optimization of dump diffuser is still an emerging field in the modern aircraft industry [1-27]. For advanced aircraft engines, the faired diffuser concept is unattractive due to the performance deterioration under a wide range of operating conditions. The flow pattern becomes more sensitive to changes in operating conditions. Therefore, the modern aircraft engines incorporate a different type of combustor inlet with dump diffuser (see Fig.1). It consists of a pre-diffuser followed by a dump region around the flame tube. Such systems are favored because of their inherent flow stability under a wide range of operating conditions and insensitivity to manufacturing resilience and thermal expansions. However, they have relatively high losses, low-pressure recovery, and long axial distances in comparison to the faired diffusers. Owing to the complexity of flow conditions and a large number of requirements, the design optimization of the combustor inlet is still an elusive problem. Note that reducing the pre-diffuser length and simultaneously increasing the opening angle to maintain the area ratio is critical because the flow tends to separate.

The flow field in the entry region of a gas turbine combustion chamber is mainly determined by the performance of the combustor diffuser. In modern times, the diffusing system customarily used by aircraft engines is the dump diffuser. The dump diffuser produces a stable flow pattern under a wide range of operating conditions. Fishenden and Stevens [9] studied the influence of the dump diffuser system. A fully annular model of dump diffuser was tested. Results showed that the presence of the flame tube (see Fig.1) has a beneficial effect on the performance and stability of flow in the pre-diffuser but no mention about the shape of the flame tube, which we are planning to optimize through this project.

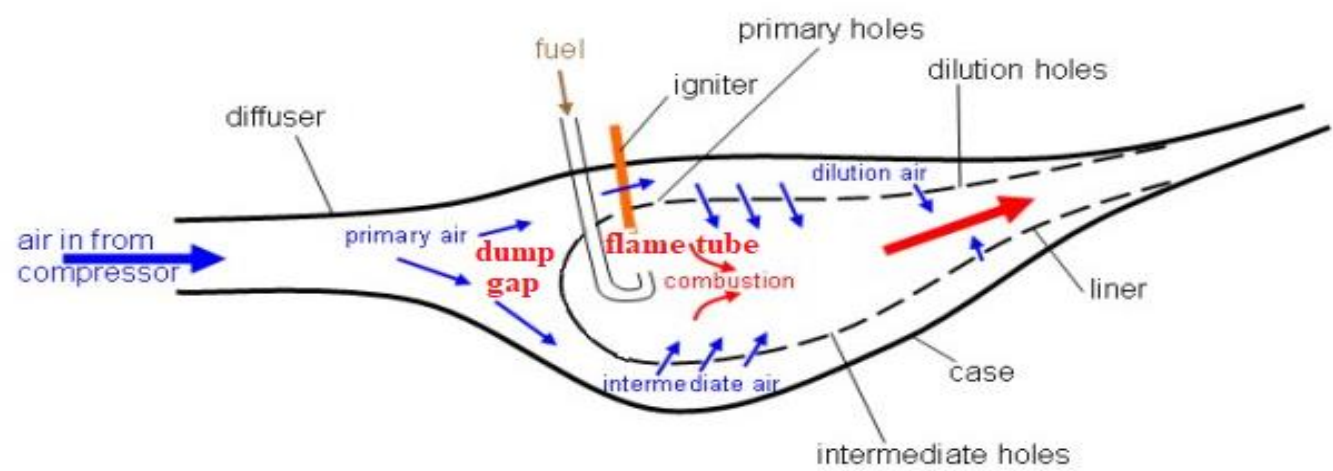

Fig. 1 Conventional shape of a flame tube in a dump diffuser [1]. 
Modern aircraft gas turbine design requires that the compressor produces a high-pressure ratio with a minimum number of stages. As a consequence, the air leaves the compressor with a high axial velocity. Effective combustion with small pressure losses can only be achieved with the low air velocities. Moreover, the air which is to be discharged into the flame tube must approach the combustor-liner admission ports rather slowly to ensure favorable conditions for the flow through them, in particular large discharge coefficients, steep jet angles, and deep penetration. A diffuser is used to reduce the average velocity of fluid flow in a duct. In subsonic flow, this reduction in velocity is achieved by gradually increasing the cross-sectional area of the duct. For an efficient diffuser, there should be an increase in static pressure and reduction in flow velocity. Note that the shape of the dump zone varies widely among engines. It is known that in addition to the geometric and fluid dynamic features that generally affect the annual diffuser performance, the characteristics of dump-diffuser combustor inlets depend on a variety of parameters, notably the dump gap. The dump gap is the distance between the flame tube head (or the dome cowling) and the pre-diffuser exit plane, referred to as pre-diffuser exit height (see Fig.1). The short dump diffusers give an advantage in gaining the thrust-to-weight (T/W) ratio of the engine. Note that the design requirements for gas turbines tend to be demand the flow fields and stress fields are very complex and must be well understood to achieve the required design efficiencies. The primary technology drivers are to reduce design cycle time and manufacturing costs.

The literature review reveals that many experimental and numerical studies have been focused on the design optimization of modern aero-gas turbine engines during the last few decades [1-27]. Those studies demonstrated that the performance of dump diffusers depends largely on the profile of the pre-diffuser, the flow field of diffuser inlet, and the distance between the head of the flame tube and the outlet of the pre-diffuser. V.R. Sanal Kumar et al. [3-6] in a series of papers demonstrated the importance of aerodynamics design optimization of dump diffusers and correlated geometric variables with various intrinsic flow features of dump diffusers for efficient combustion. Selvakarthick et al. [7] concluded that a dump diffuser with an adjustable flame tube for getting different dump gap and orientation may be a future viable option for warranting high-performance aero-gas turbine engines with maximum static pressure recovery under a wide range of operating conditions. Walker et al. [14] was investigated experimentally a diffuser with a high dome flow rate and high dome depth. The authors revealed the interaction between the diffuser and downstream geometry and explained how this interaction varied with changes in diffuser geometry. Ainley [16], Johnston [17], and Howard [18] reported the characteristics of annular diffusers, but without taking into account flame tube effects. Sovran, Klomp, and E.D. [19] shown the correlation between the performance parameters of the plane, conical, and annular diffusers. However, the effect of flame tubes is not considered. Biaglow, J.A. [20] demonstrated the advantage of dump type diffuser configurations compared to faired diffusers. Wagner, W.B, Tanrikut, S, and Sokolowski, [21] investigated the effects of flow splits on the performance of a curved wall dump diffuser with a canted pre-diffuser. Klein, [8] reported that the main fluid dynamics parameter which affects the diffuser performance is the area fraction blocked by the boundary layer displacement thickness $(\delta)$. Srinivasan and Freeman et al. [23] attempted to optimize the dump gap ratio. Japikse [22] highlighted that the static pressure recovery is insensitive to a Mach number below 0.25 and has almost negligible influence up to a Mach number of 0.60. Note that, a Mach number of around 0.2-0.3 is more typical at the inlet of a modern combustion chamber. Prakash Ghose et al. [24] studied numerically the effect of dome shape on the static pressure recovery in a dump diffuser at different inlet swirl. V.R. Sanal Kumar et al. [6] observed that at a sufficiently small dump gap and with high turbulence intensity the flame tube head proximity creates back pressure on the pre-diffuser discharge flow and displaces it towards the walls and thus inhibits separation and thereby the pressure recovery on the pre-diffuser significantly increases. Figure 2(a-d) shows the evolution of the dump diffuser design advancement for modern aircraft engines with various types of flame tubes.

In our connected work, Aravind et al. [1,2] reported that the dump diffuser with geometrically optimized prediffuser upstream port and its divergent cone along with the aerodynamically-shaped adjustable flame tube for attaining a variable dump gap effect is a profitable and viable option for improving the performance characteristics of aero gas turbine engines under a wide range of operating conditions. Towards meeting further design objectives, in this connected project, using a two-dimensional (2D) standard k- $\varepsilon$ turbulence model, parametric analytical studies have been carried out to examine the flow features through a dump diffuser facilitated with NACA airfoilshaped flame tubes. The reason for choosing the NACA series airfoil is due to the fact that it produces high profile drag and form drag in the flow field even with an aerodynamically shaped geometry. It will obviously contribute towards increasing the static pressure recovery for meeting the lucrative design objectives of the dump diffusers for improving the performance characteristics of aero gas turbine engines under a wide range of operating conditions, which is examined herein using a validate viscous flow solver. Due to the Covid-19 pandemic the planned experimental validation will be carried out in the next phase. 


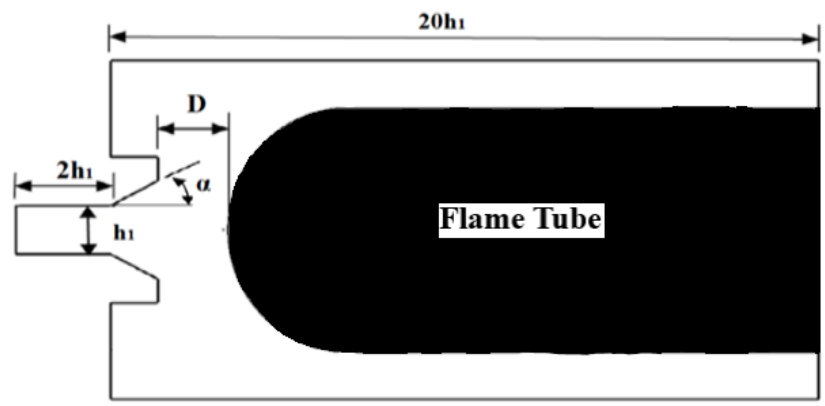

(a) Honami and Morioka [25] (ASME-1990)

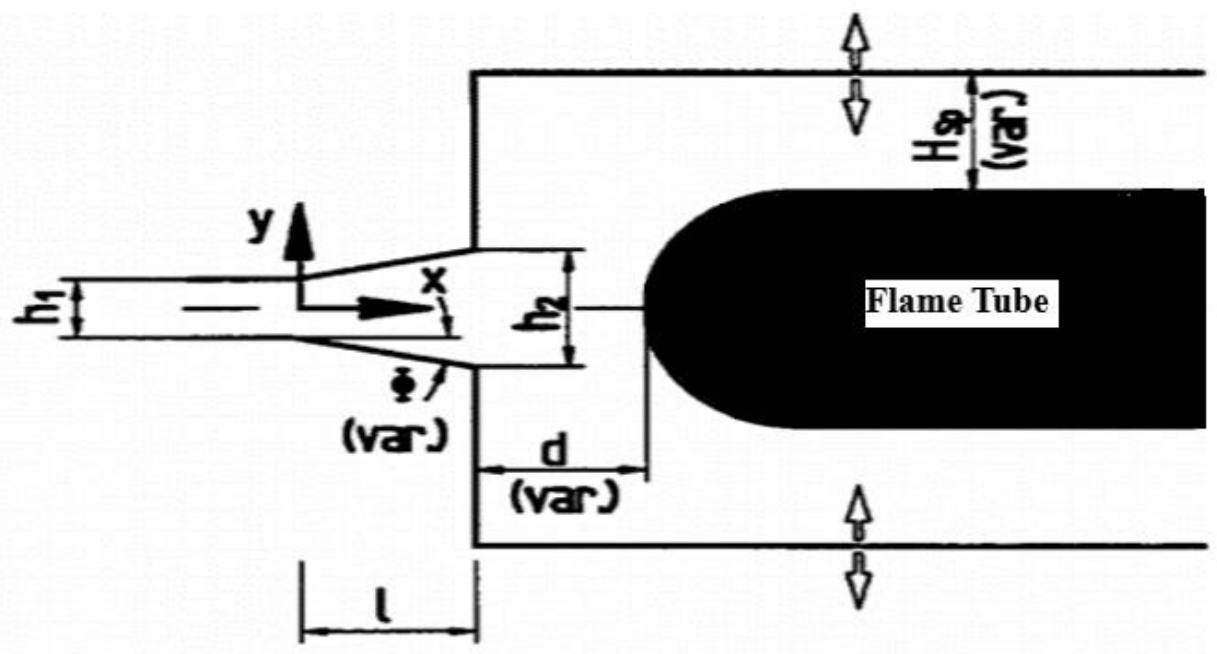

(b) Hestermann et.al. [27] (ASME -1994)

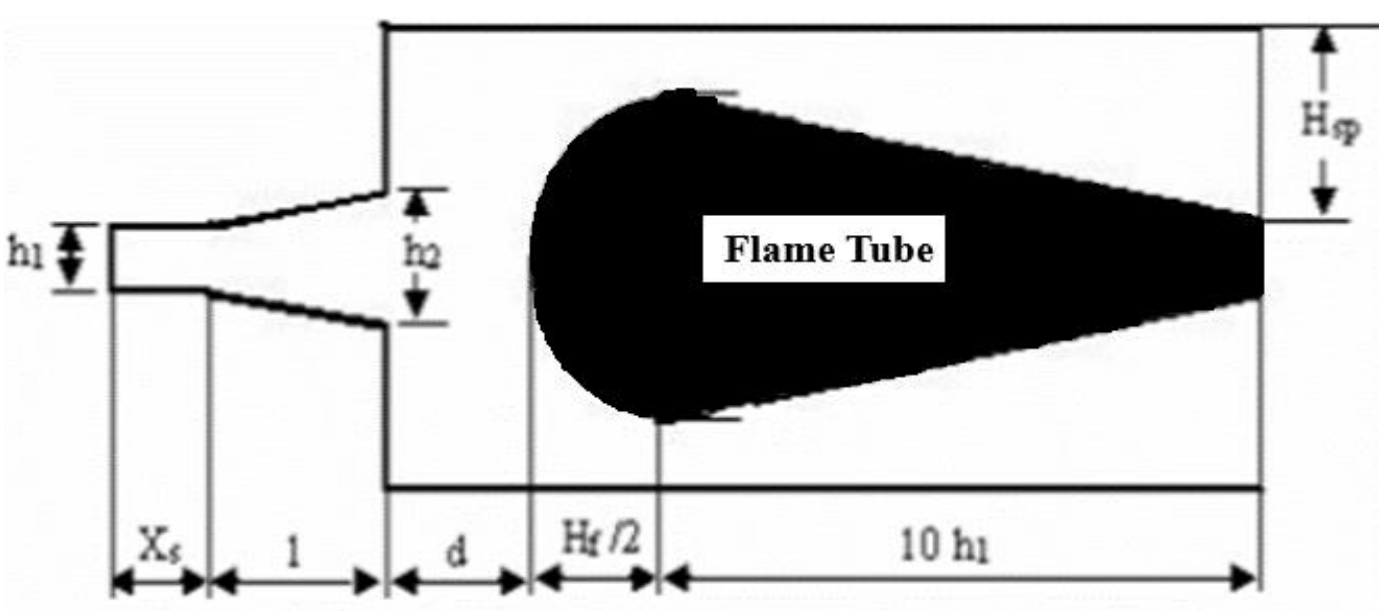

(c) V. R. Sanal Kumar et.al., [6] (AIAA - 2007) 


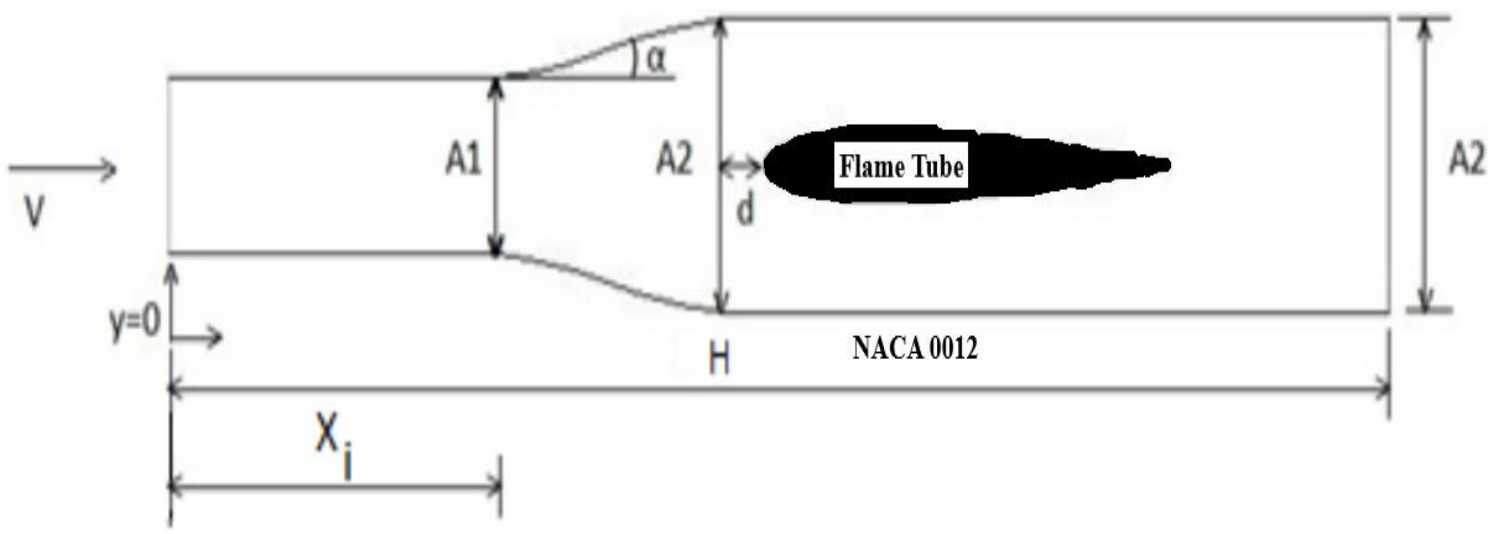

(d) Selvakarthick et.al., [7] (AIAA - 2016)

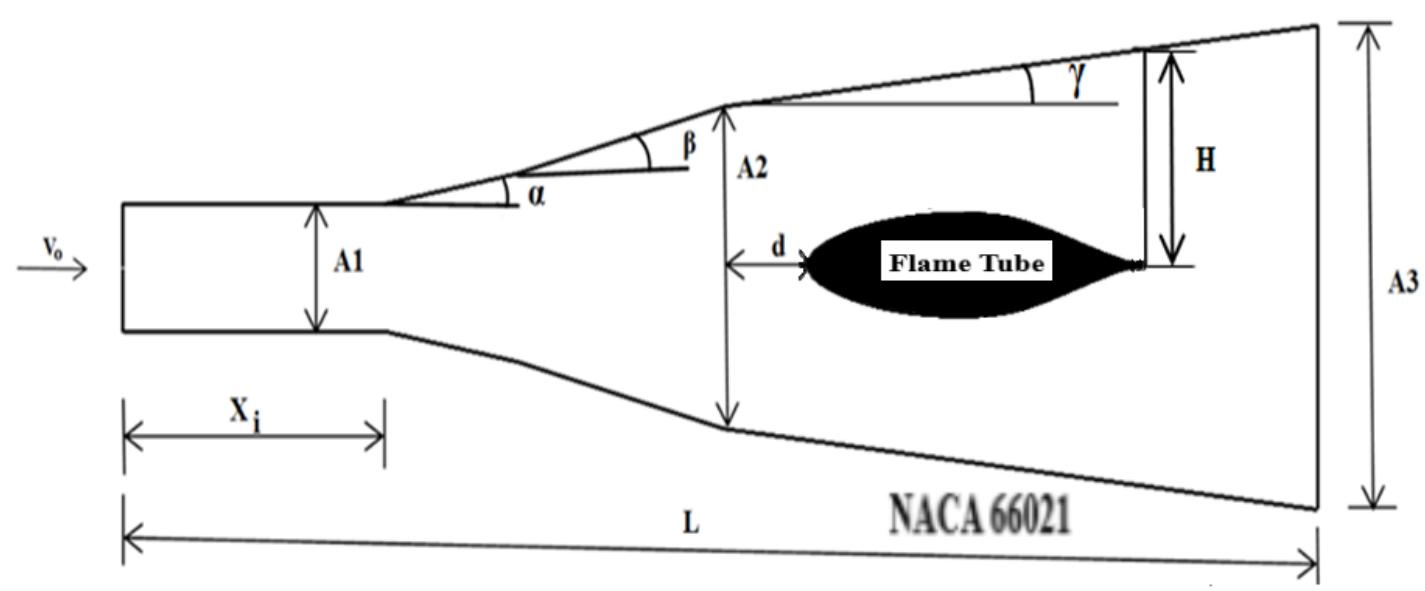

(e) Aravind and Sabarinathan et al. [1] (AIAA - 2019)

Fig. 2(a-e) Evolution of the Dump Diffuser Designs

\section{Numerical Methodology}

Numerical simulations have been carried out using a 2D standard $k-\varepsilon$ turbulence model. The model invoked the control volume technique. The viscosity is estimated from the Sutherland formula. As a part of the model validation, our results are compared with the benchmark data [25]. Figure 3 shows the comparison of the coefficient of pressure distribution at the flame dome (radially) with the experimental data of Honami and Morioka [25]. It is crystal clear from Fig.3 that our model and its code of solution are validated qualitatively for conducting numerical exercises with the NACA series-shaped flame tubes. The diffuser geometric variables and material properties were known a priori. An initial wall temperature and inlet gas temperature were specified. On the solid walls, the no-slip boundary condition was imposed. The CFL number was taken as 1 for all computations. Ideal gas was selected as the working fluid. The axial velocity at the pre-diffuser inlet was prescribed. The inlet turbulence intensity was taken as $8 \%$ and the inlet dissipation rate was calculated from the inlet turbulence intensity. Constant static pressure was specified at the outlet of the domain. It is evident from Fig. 3 that the standard k- $\varepsilon$ turbulence model is better than the RNG k- $\varepsilon$ turbulence model for this study. Note that Launder and Spalding [28] have successfully used the standard k- $\varepsilon$ turbulence model by minimizing unknowns and presenting a set of equations that can be applied to numerous turbulent applications. The model is verified using a closed-form analytical model satisfying the Sanal flow choking condition [29,30]. 


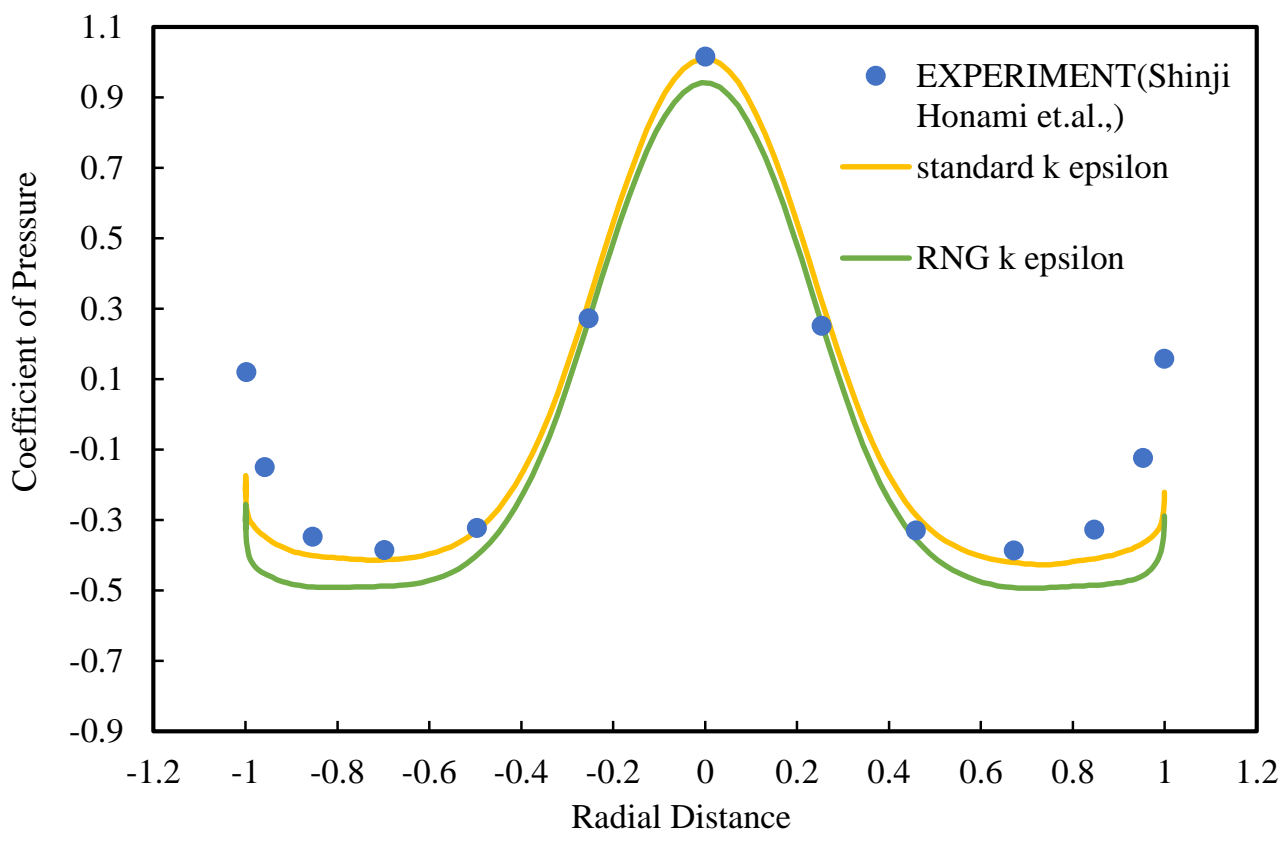

Fig. 3 Comparison of the coefficient of pressure distribution at the flame dome (radially) [1].

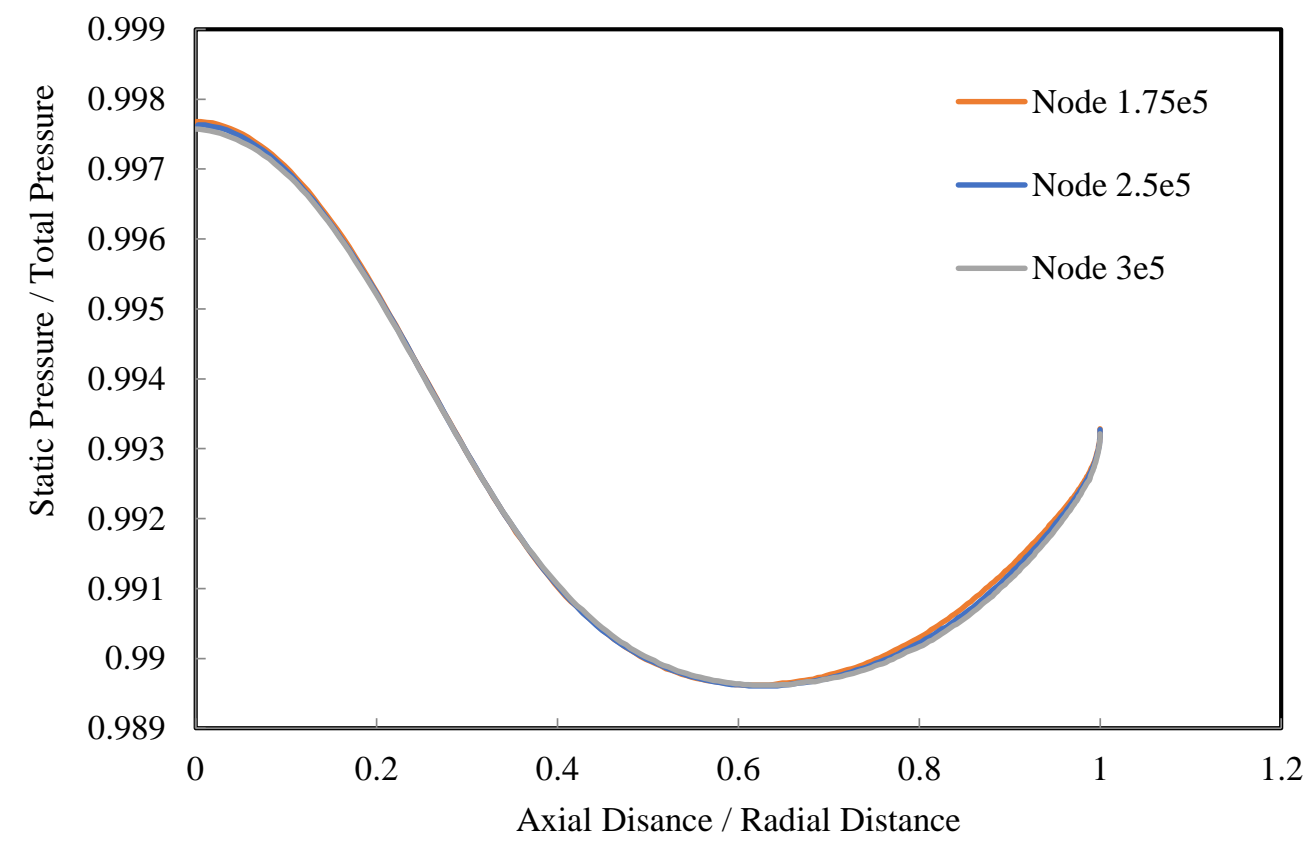

Fig. 4 Grid refinement study for 2D model validation [1]. 


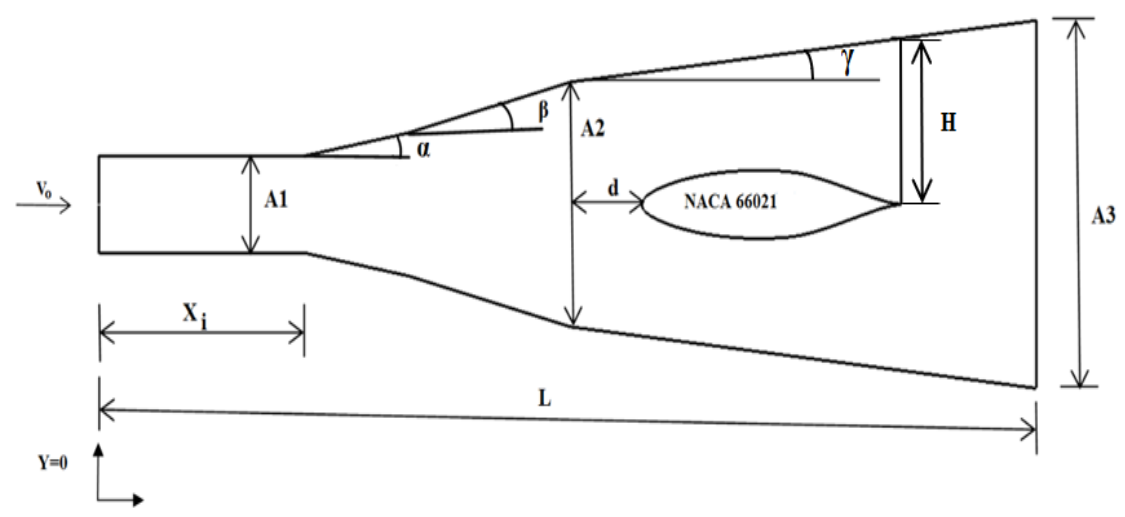

Fig. 5 The physical model of the dump diffuser with multiple pre-diffuser divergent angles facilitated by an aerodynamically shaped flame tube.

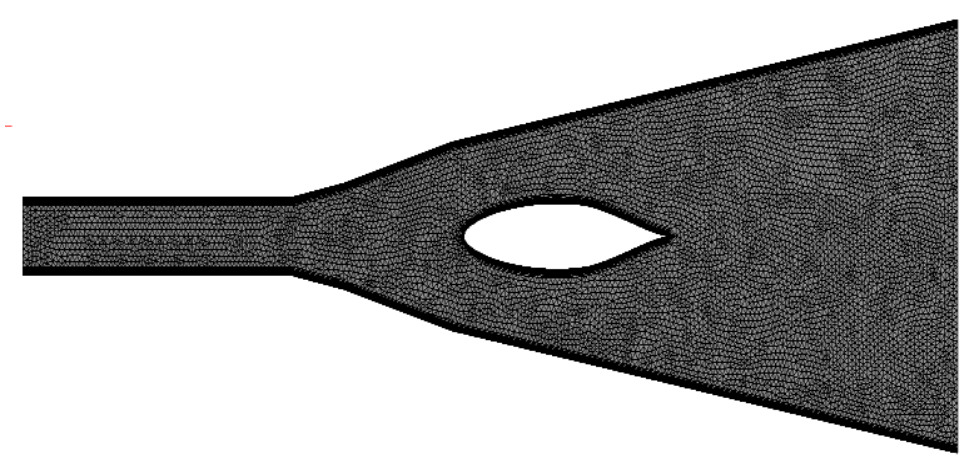

Fig. 6 2D grid system in the computational domain

Figure 5 shows the physical model of the dump diffuser with multiple pre-diffuser divergent angles facilitated by an aerodynamically shaped flame tube. Figure 6 shows the two-dimensional grid system in the computational domain. In the numerical model, the turbulent kinetic energy, $\mathrm{k}$, and its rate of dissipation, $\varepsilon$, are obtained from the following transport equations:

For turbulent kinetic energy $k$ [31],

For dissipation $\varepsilon$

$$
\frac{\partial(\rho k)}{\partial t}+\frac{\partial\left(\rho k u_{i}\right)}{\partial x_{i}}=\frac{\partial}{\partial x_{i}}\left[\frac{\mu_{t}}{\sigma_{k}} \frac{\partial k}{\partial x_{i}}\right]+2 \mu_{t} E_{i j} E_{i j}
$$

where

$$
\frac{\partial(\rho \varepsilon)}{\partial t}+\frac{\partial\left(\rho \varepsilon u_{i}\right)}{\partial x_{i}}=\frac{\partial}{\partial x_{i}}\left[\frac{\mu_{t}}{\sigma_{\varepsilon}} \frac{\partial \varepsilon}{\partial x_{j}}\right]+C_{1 \varepsilon} \frac{\varepsilon}{k} 2 \mu_{t} E_{i j} E_{i j}-C_{2 \varepsilon} \rho
$$

$u_{i}$ represents velocity component in corresponding direction.

$E_{i j}$ represents the component of the rate of deformation.

$\mu_{\mathrm{t}}$ represents eddy or turbulent viscosity.

$$
\mu_{t}=\rho C_{\mu} \frac{k^{2}}{\varepsilon}
$$

The equations also contain some of the adjustable constants like $\sigma_{\mathrm{k}}, \sigma_{\varepsilon}, \mathrm{C}_{1 \varepsilon}, \mathrm{C}_{2 \varepsilon}$. Where, $\sigma_{\mathrm{k}}=1.00, \sigma_{\varepsilon}=1.30$, $\mathrm{C}_{1 \varepsilon}=1.44, \mathrm{C}_{2 \varepsilon}=1.92$, and $\mathrm{C}_{\mu}=0.09$ which suitable to work fairly well for a wide range of wall-bounded and free shear flows. These values are standard model constants one most widely accepted, which have been determined from experiments with air and water for fundamental turbulent shear flows [31].

We have carried out comprehensive numerical studies on the dump diffuser facilitated with various types of airfoil-shaped flame tubes, viz., NACA series, Geo 775, S 1014, Eppler series and compared each other. In all the cases the initial and boundary conditions are maintained the same. After detailed parametric studies, the NACA 66-021 airfoil-shaped flame tube is selected, which experiences high form drag and profile drag in the flow field, which contributes toward an increase in the static pressure recovery significantly among the cases considered herein. 


\section{Results and Discussion}

It is well known that in an aircraft industry, weight of each design plays a major role which directly affects the efficiency of an aircraft. So instead of using many axial stages in a compressor to get a required amount of pressure in the flow to get efficient combustion in the combustion chamber, we can reduce the number of axial stages by using the optimized dump diffuser model which gives required pressure with the shortest possible length at a wide range of operating conditions. Towards meeting this objective, we have carried out comprehensive in silico studies. Numerical simulations are carried with low inlet velocity in the range of 30-90 $\mathrm{m} / \mathrm{s}$, which ensures effective combustion [1]. During the parametric studies, we found that the thickness-to-chord ratio $(t / c)$ of the flame tube is having bearing on the static pressure recovery. If the angle of divergent is getting increased continuously after the second divergent angle $(\beta)$ then there will be a chance of flow gets separated, so there should be a requirement for a slight decrease in the third divergent angle $(\gamma)$ to make the flow to be attached even at the downstream when compared with the second divergent angle ( $\beta$ ) (see Fig.5). We conducted a computational study on the dump diffuser with various NACA series airfoils to know the effect of the flame tube geometry in pressure recovery. From Fig. 2(a), It shows that authors used the flame tube where the aerodynamic shape was not much concentrated for an output. Because of an increase in flame tube depth, the flow tends to get accelerated due to its boundary layer interaction between the non-aerodynamic shaped flame tube and the straight-walled construction as per flow characteristics based on the Sanal flow chocking condition [30]. This behavior occurs on both the upper and lower side of the non-aerodynamic shaped flame tube inside a dump diffuser which causes major static pressure loss on the flow passing to the combustion section. Hence from Fig. 2(b) Hestermann et.al. [27] decreased the flame tube depth slightly compared to Honami et.al. [25] design which increased the static pressure recovery on the output due to its low boundary layer blockage between the walls. This initiative makes the dump diffuser designers to concentrate over the flame tube depth and its design inside the dump diffuser. Thereby flame tube added as an important and interesting parameter which should be optimized inside the dump diffuser to achieve the desired output. From here, the evolution of flame tube design on the dump diffuser started. In Fig. 2(c), V. R. Sanal Kumar et.al., [6] approached this problem differently by designing the cone-shaped flame tube which increased the static pressure recovery on output when compared to previous designs. But, in a cone-shaped flame tube before the starting of the divergent wall section, there is a contraction due to the curve radius $(\mathrm{R})$ on the cone-shaped flame tube inlet and the straight-walled diffuser. Due to the high curve radius $(\mathrm{R})$ on the cone-shaped flame tube, the flow tends to lose its energy which directly affects the output. In Fig. 2(d), Selvakarthick et.al., [7] increased the divergent wall angle ( $\alpha)$ after the straight-walled pre-diffuser to reduce the contraction characteristics on the flow by placing the flame tube in the dump diffuser. Selvakarthick et.al., [7], also introduced the aerodynamically shaped flame tube design with NACA 0012 airfoil, which provided maximum static pressure recovery compared to the old designs. At the same time due to its low thickness to chord ratio ( $t / c)$ of NACA 0012 airfoil, the profit of keeping an aerodynamic-shaped flame tube was considered to be less. Aravind and Sabarinathan et.al. [2], replaced the NACA 0012 with the NACA 66-021 shaped flame tube (see Fig. 2e) in the dump diffuser for getting better performance based on the physical insight gained throw the in silico simulations while characterizing airfoil flow features in a wall-bounded flow system at subsonic inflow conditions. Authors reported that NACA 66021 has high profile drag and form drag on the flow [2], which could increase the static pressure recovery and compliment with the coupled effect on multiple divergent walls on dump diffuser. Authors further reported that the thickness to chord (t/c) ratio of an airfoil is an important parameter for the flame tube to achieve the maximum possible static pressure recovery on the dump diffuser [2]. Experienced gained from the comprehensive in silico simulation prompted the authors to examine the flow features of various dump diffusers with various symmetrical airfoils having different $(\mathrm{t} / \mathrm{c})$ ratios to optimize the $\mathrm{t} / \mathrm{c}$ ratio of a flame tube for meeting the design objectives of modern aircraft engines lucratively.

It is evident from the numerical results presented in Figs. 8-26 that the NACA 66-021 airfoil-shaped flame tube has a maximum static pressure recovery than the other cases considered herein (see Table-1). It can be seen from Fig. 21 that variations of the turbulent intensity in given inflow conditions will not affect the increasing static pressure recovery on the dump diffuser with the standard $k-\varepsilon$ turbulence model. In a few cases due to low thickness to chord ratio $(\mathrm{t} / \mathrm{c})$, a significant flow separation was developed leading to a decrease in the static pressure recovery on the dump diffuser. We observed that instead of having a straight wall, multiple opening angles will have a significant effect on decreasing total pressure losses on the dump diffuser. As seen in Fig. 13, the flow gets separated at the NACA 0015 airfoil shape flame tube presumably due to its low $\mathrm{t} / \mathrm{c}$ ratio. It makes the flame tube as an ineffective device on the dump diffuser. Note that the numerical results presented herein give us the valuable physical insight of the internal flow features of the dump diffuser with an aerodynamically shaped flame tube. There is a limiting length of the pre-diffuser and above that limit, there will be a significant boundary layer blockage and as a result, the velocity will get increased at the end of the pre-diffuser leading to a total pressure loss. Through the parametric analytical studies, we observed that if the first divergent angle is very large then there will be a flow separation occurs on near the walls of the dump diffuser, which increases the energy loss of the flow. The optimized first divergent angle is $10^{\circ}$ for the given inflow conditions on the dump diffuser. It is evident from the numerical results that the second divergent cone angle $14^{0}$ will have a significant 
effect on increasing the static pressure recovery. The optimum second divergent angle is required because, if the second divergent angle is too large then there will be an increase in total pressure loss due to flow separation. The area ratio also decides the amount of diffusion of the flow throughout the aerodynamically shaped flame tube from the pre-diffuser exit. So, the area ratio should be optimized to avoid flow separation and flow recirculation ahead of the dump gap. Table-1 shows the comparison of the maximum static-to-total pressure ratio $\left(\mathrm{P} / \mathrm{P}_{\mathrm{o}}\right)$ of the investigated flame tube configurations on the dump diffuser. It can be clearly discerned from the Table-1 that the optimized dump diffuser with NACA 66021 airfoil achieved the high static pressure recovery than the other airfoil-shaped flame tubes considered herein under identical inflow conditions.

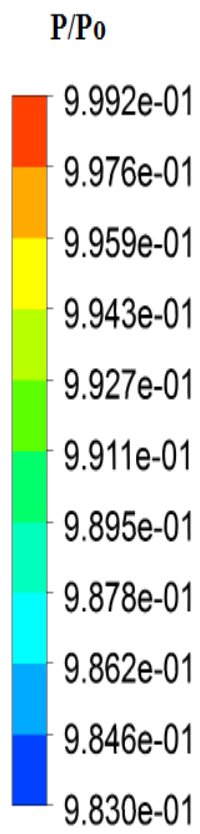

Fig. 7 Non-dimensional pressure contour variations in the computational domain of the dump diffuser with multiple pre-diffuser divergent angles along with NACA 66021 airfoil.

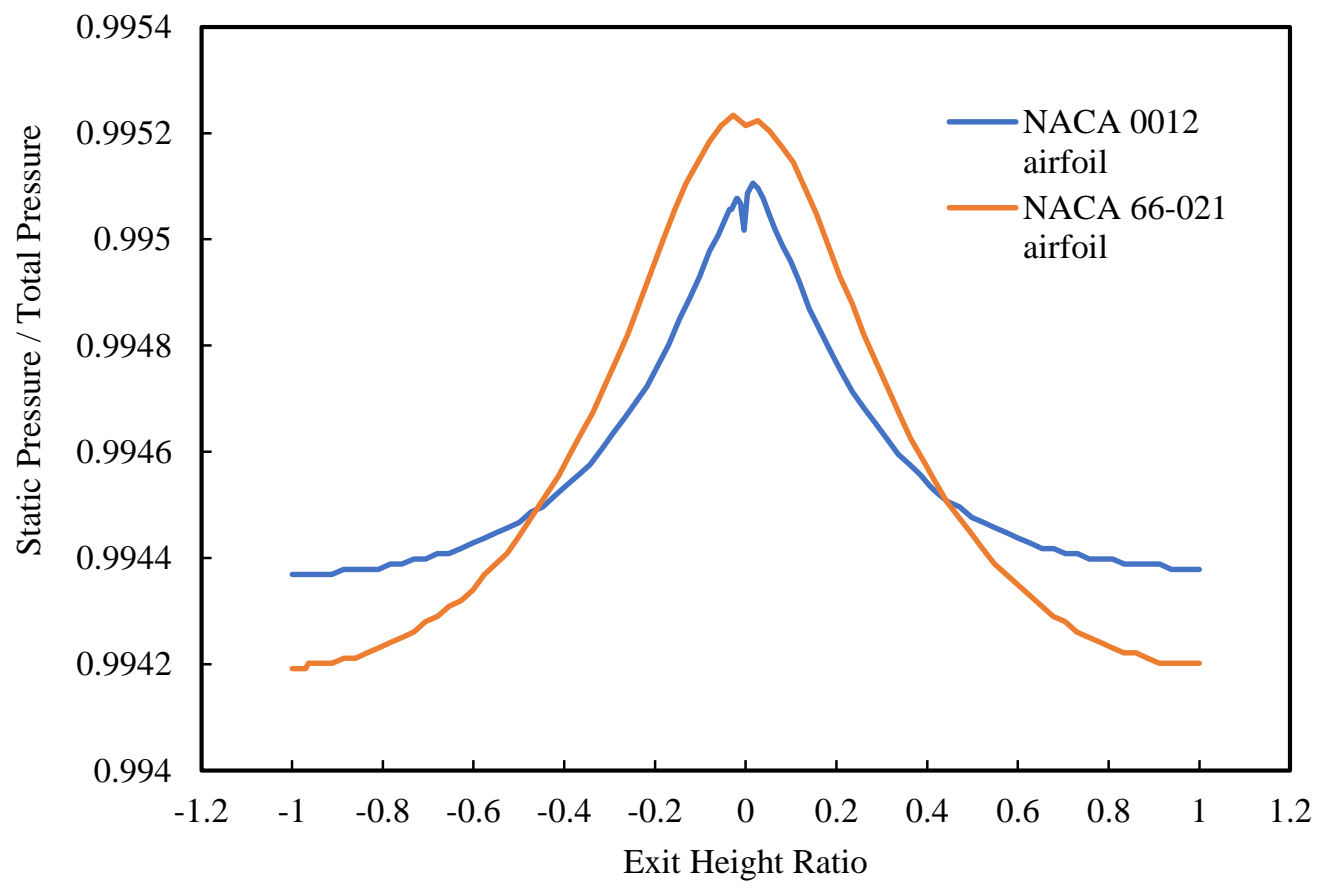

Fig. 8 Comparison of the static pressure recovery on the dump diffuser with airfoils NACA 0012 and NACA 66-021. 


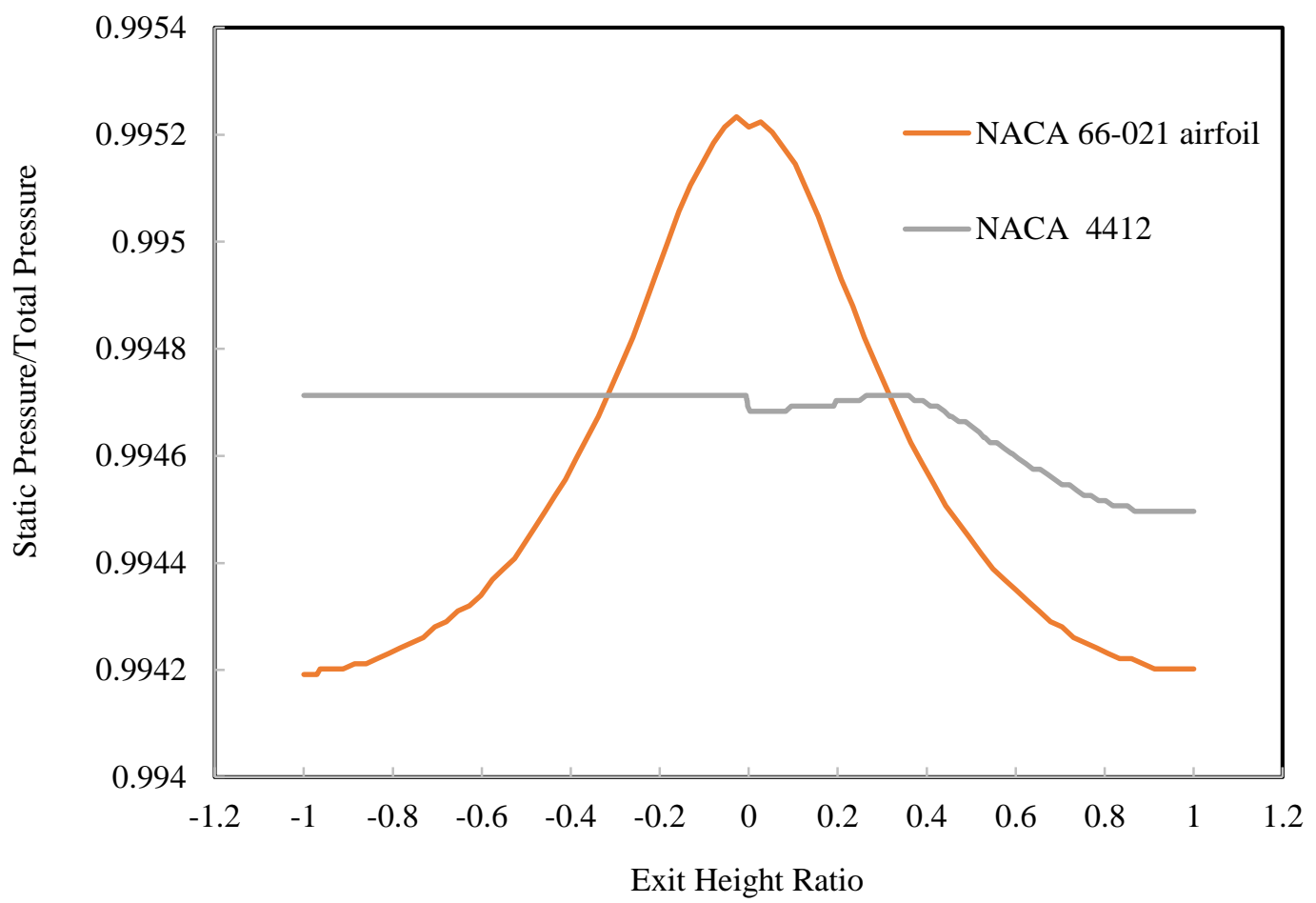

Fig. 9 Comparison of the static pressure recovery on the dump diffuser with airfoils NACA 4412 and NACA 66-021.

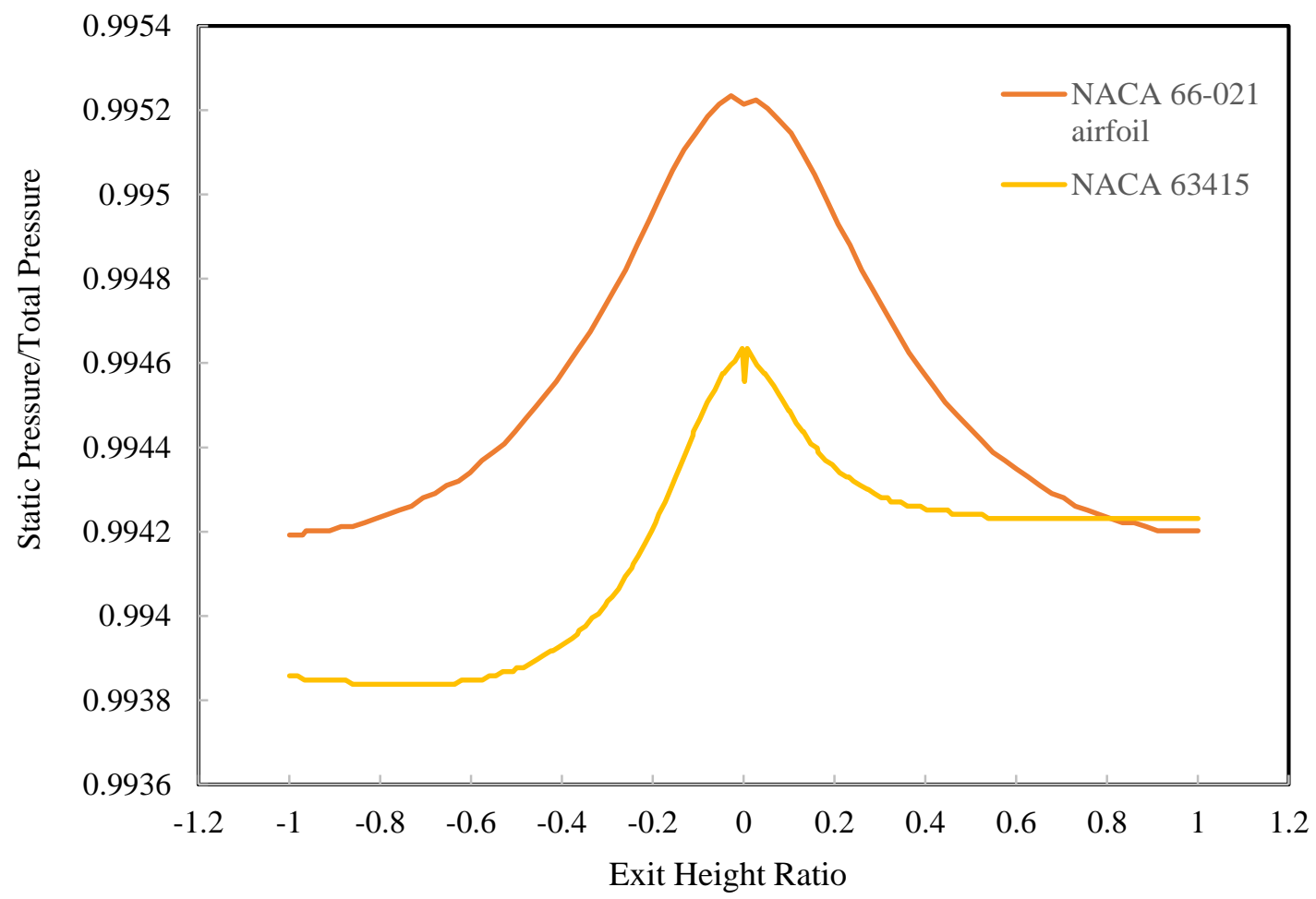

Fig. 10 Comparison of the static pressure recovery on the dump diffuser with airfoils NACA 63415 and NACA 66-021. 


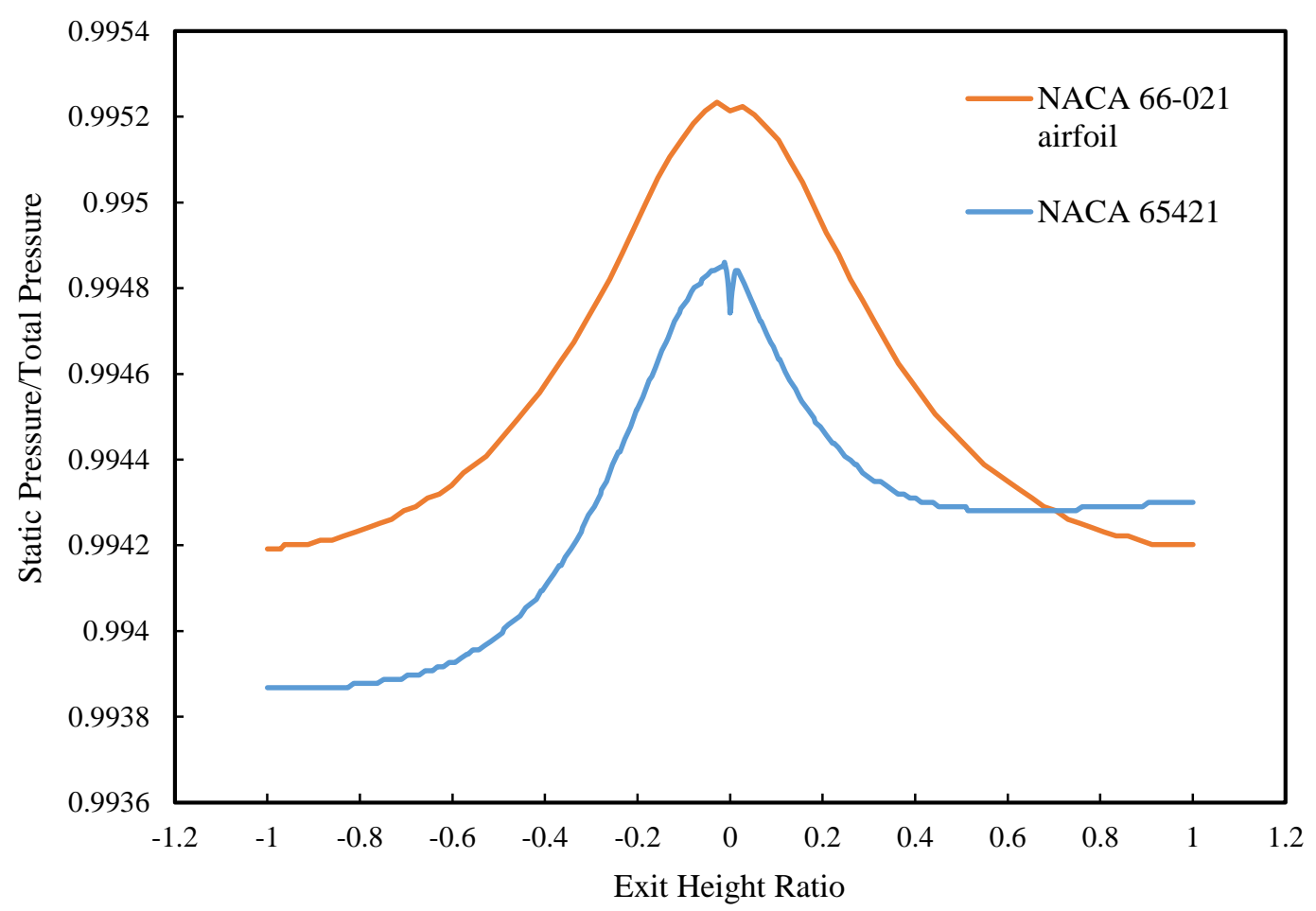

Fig. 11 Comparison of the static pressure recovery on the dump diffuser with airfoils NACA65421 and NACA 66-021.

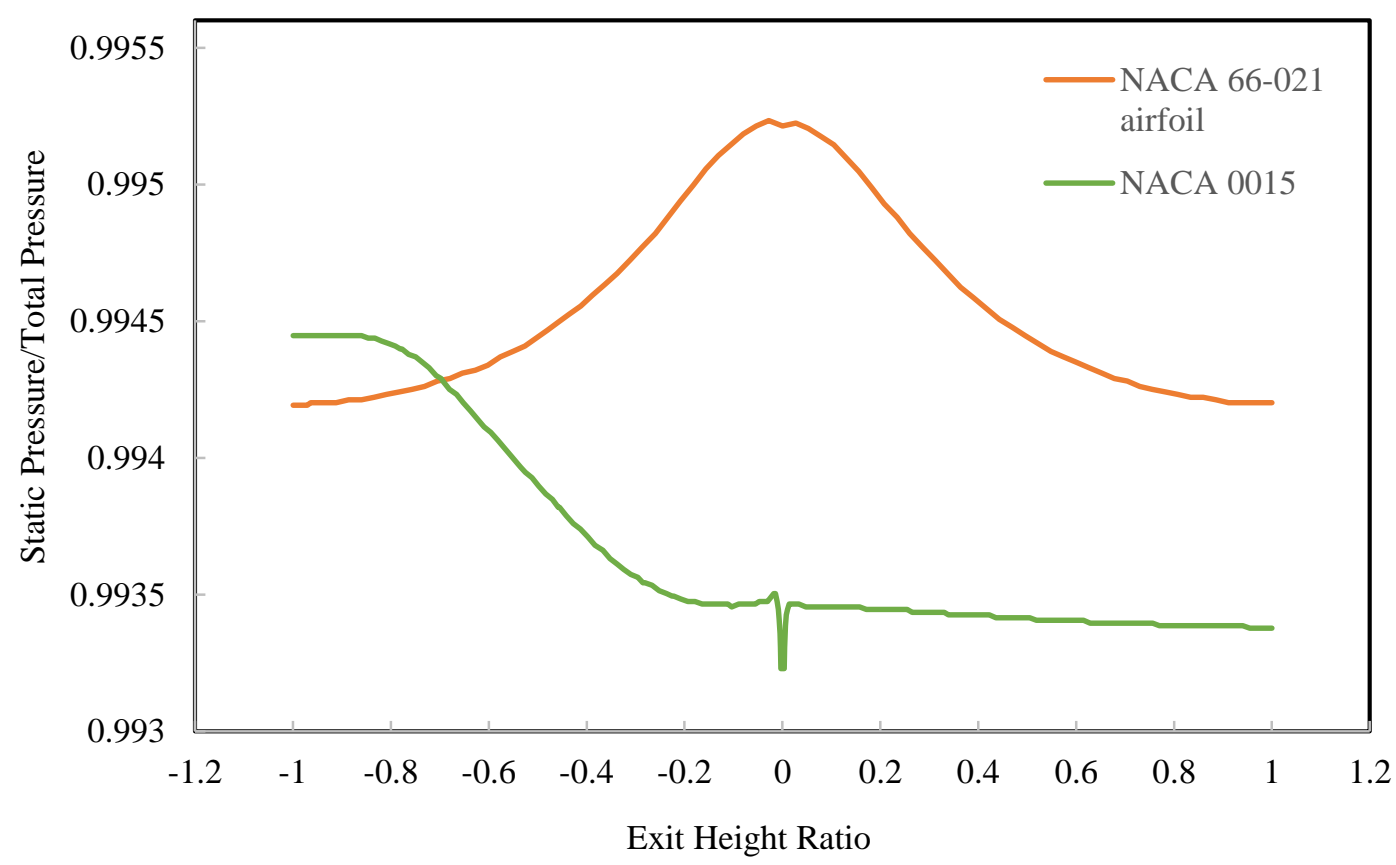

Fig. 12 Comparison of the static pressure recovery on the dump diffuser with airfoils NACA 0015 and NACA 66-021. 


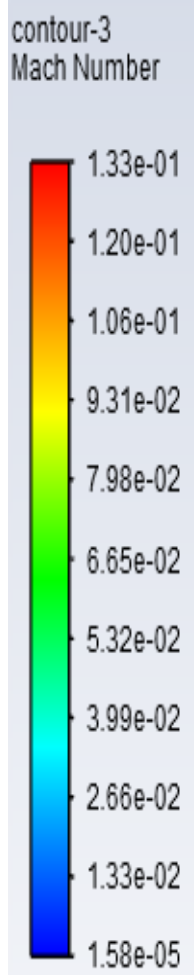

Fig. 13 Non-dimensional Mach Number contour variations in the computational domain of the dump diffuser with multiple pre-diffuser divergent angles with airfoil NACA 0015.

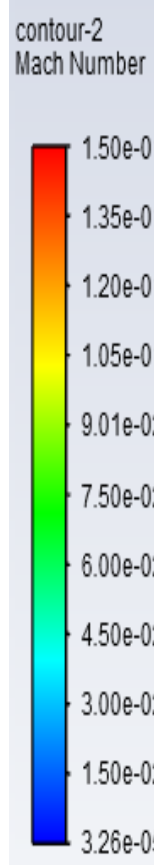

Fig. 14 Non-dimensional Mach Number contour variations in the computational domain of the dump diffuser with multiple pre-diffuser divergent angles with airfoil NACA 16021. 


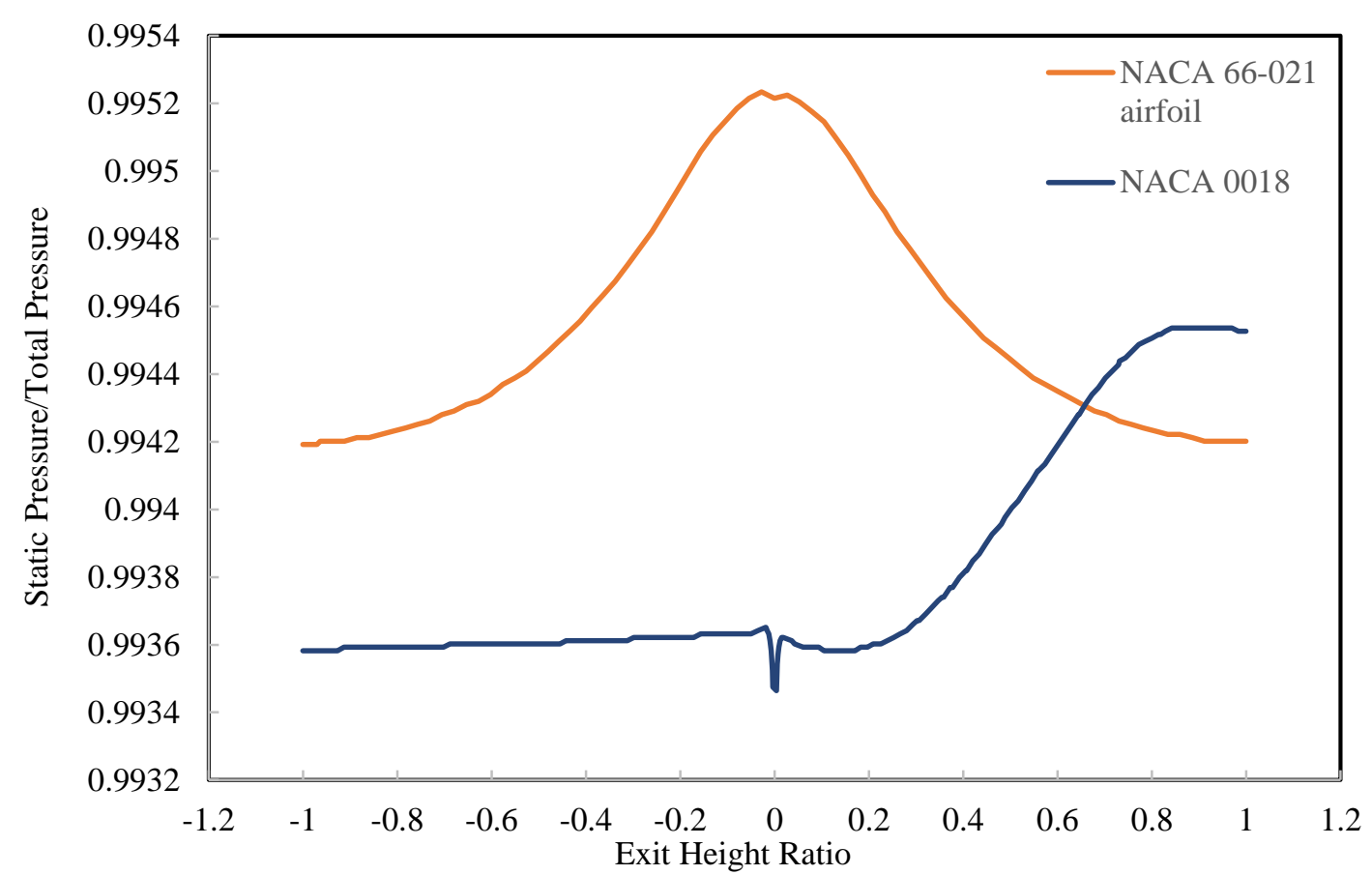

Fig. 15 Comparison of the static pressure recovery on the dump diffuser with NACA 0018 and NACA 66-021.

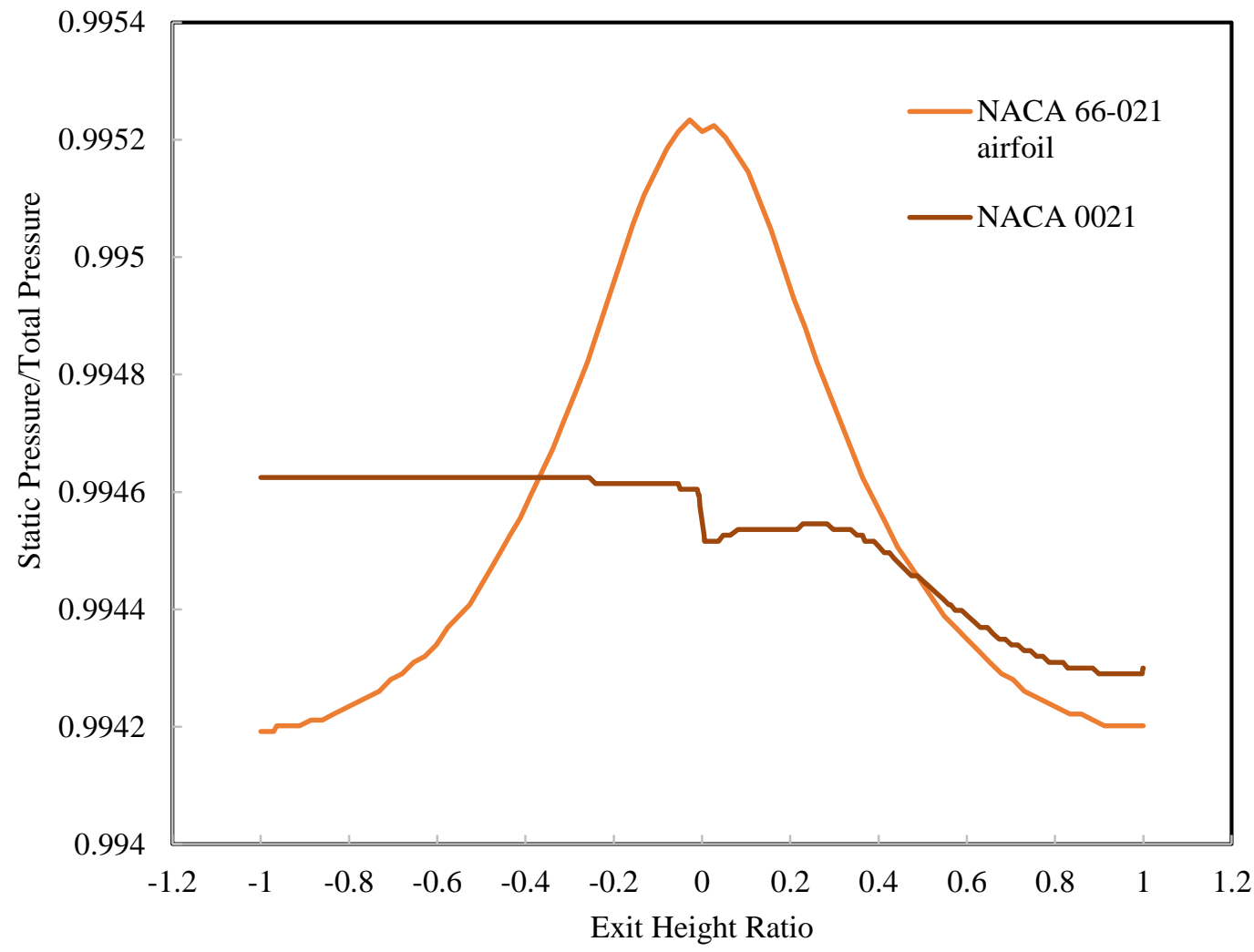

Fig. 16 Comparison of the static pressure recovery on the dump diffuser with NACA 0021 and NACA 66-021. 


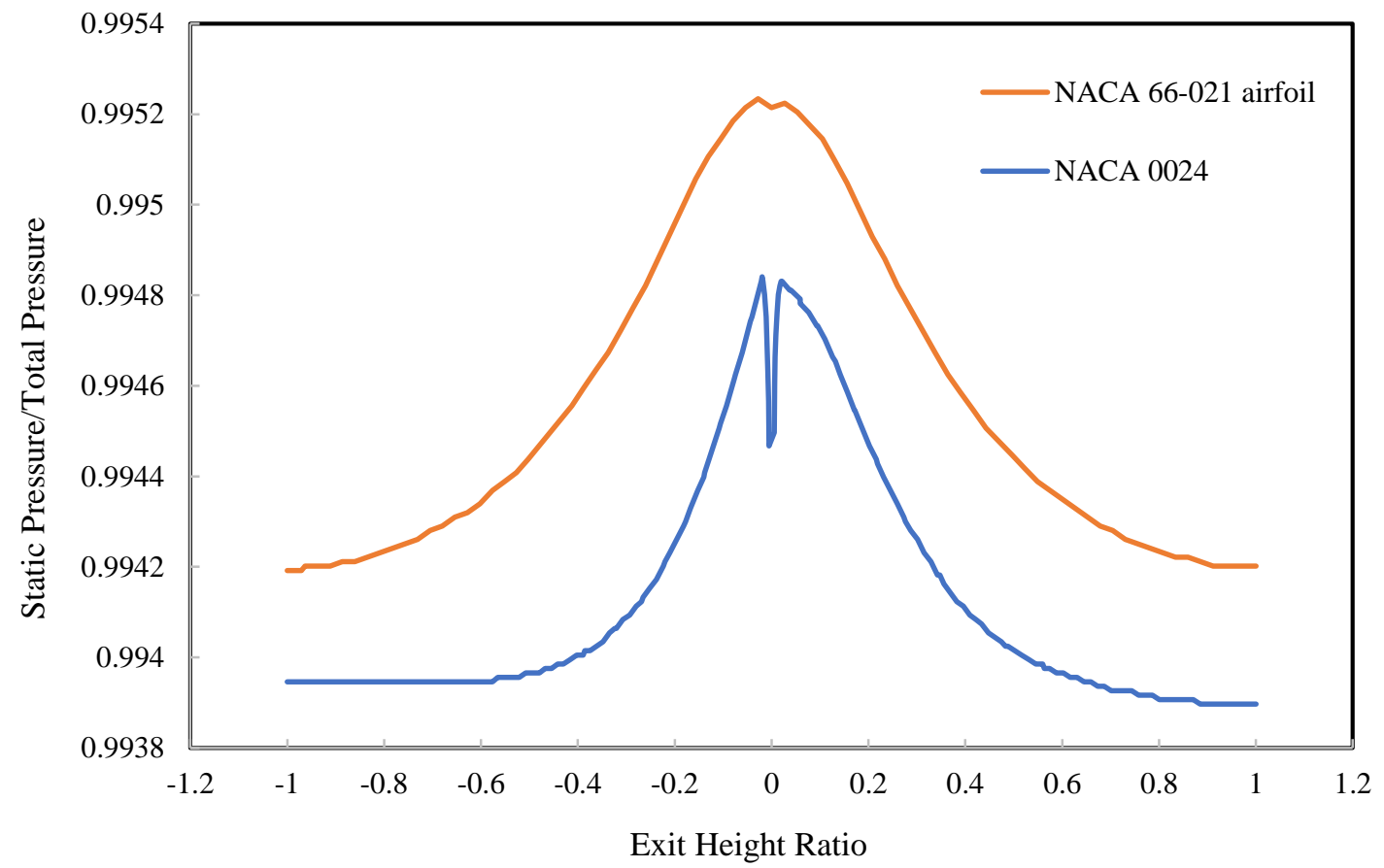

Fig. 17 Comparison of the static pressure recovery on the dump diffuser with airfoils NACA 0024 and NACA 66-021.

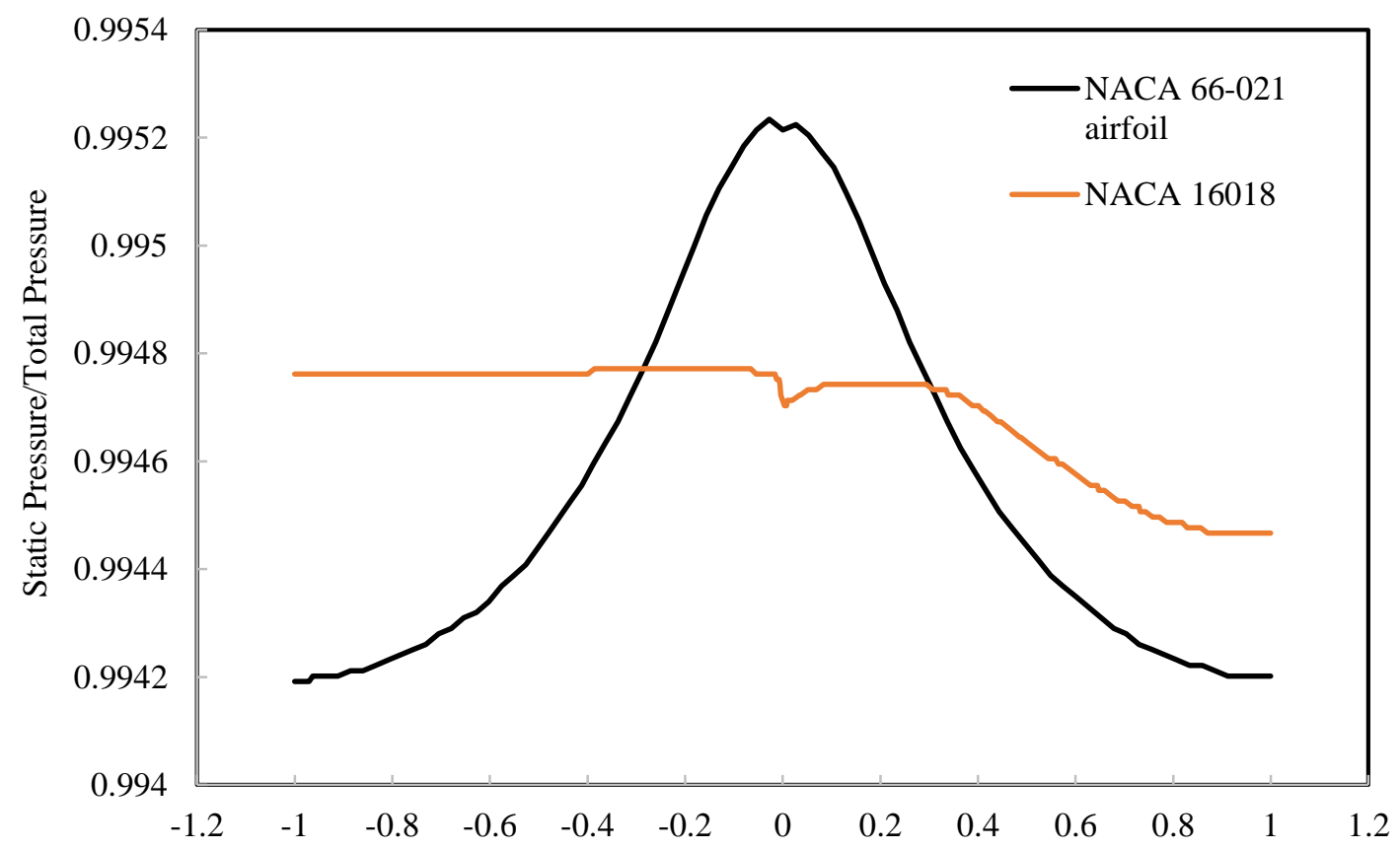

Exit Height Ratio

Fig. 18 Comparison of the static pressure recovery on the dump diffuser with airfoils NACA 16018 and NACA 66-021. 


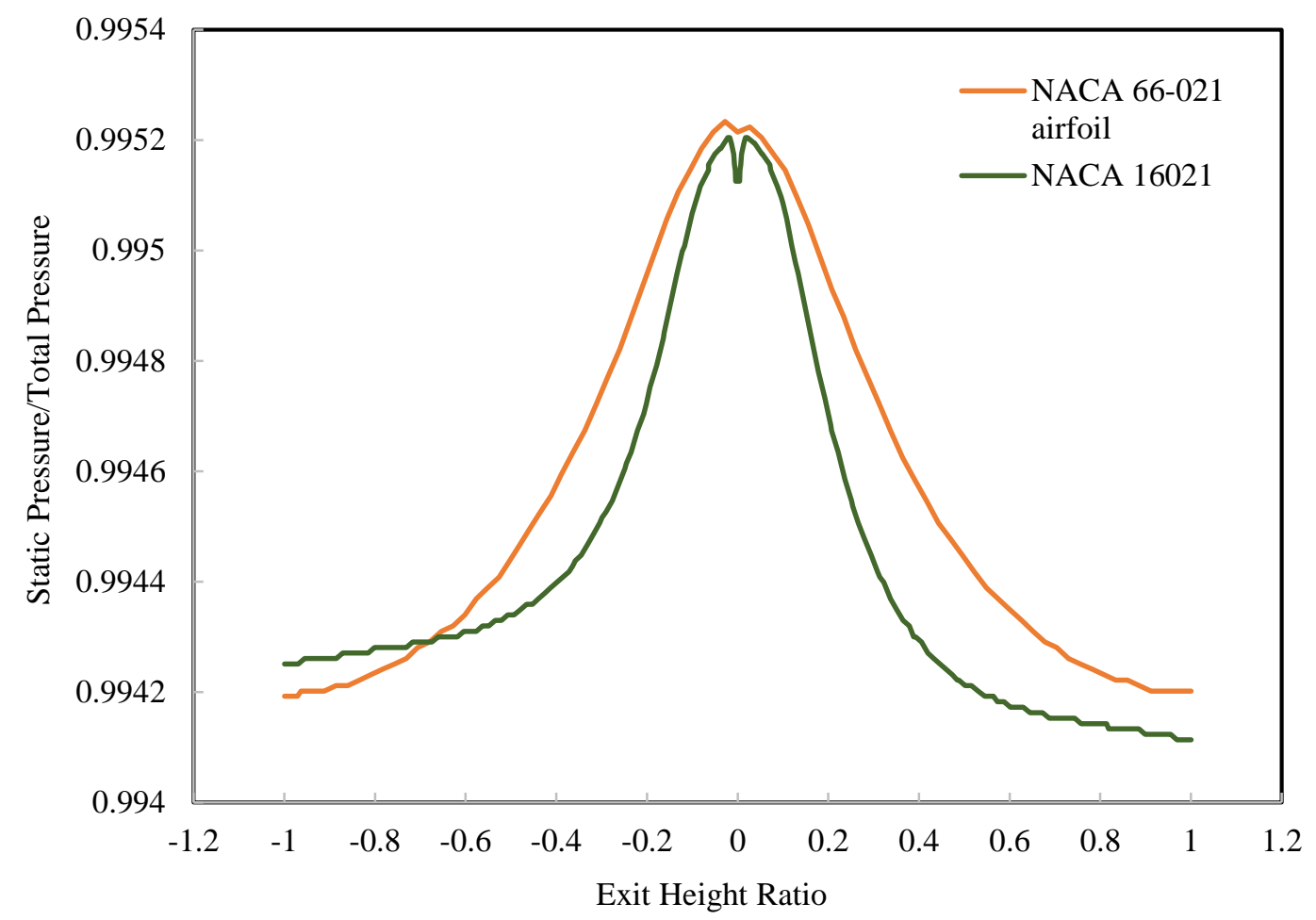

Fig. 19 Comparison of the static pressure recovery on the dump diffuser with airfoils NACA 16021 and NACA 66-021.

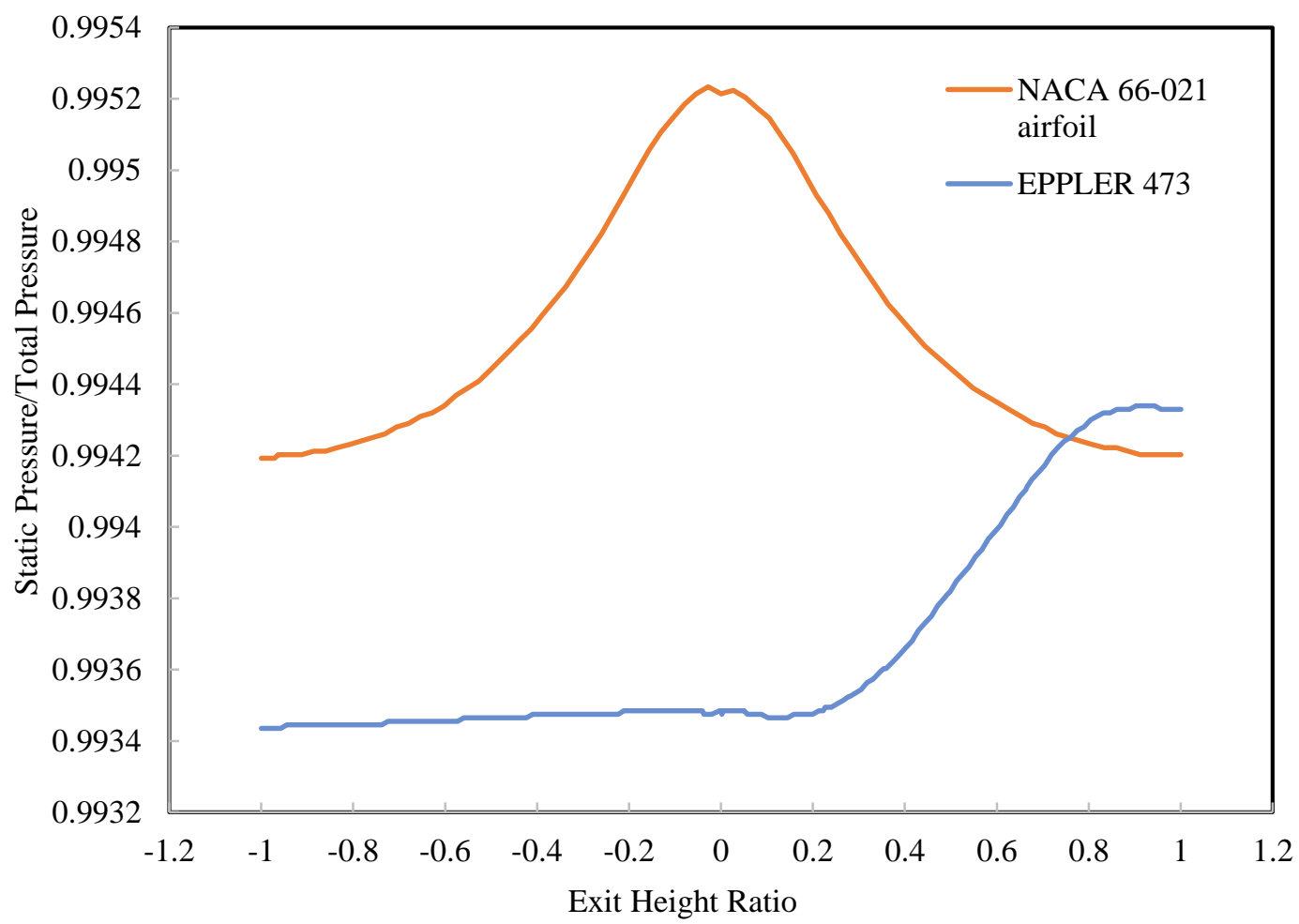

Fig. 20 Comparison of the static pressure recovery on the dump diffuser with airfoils EPPLER 473 and NACA 66-021. 


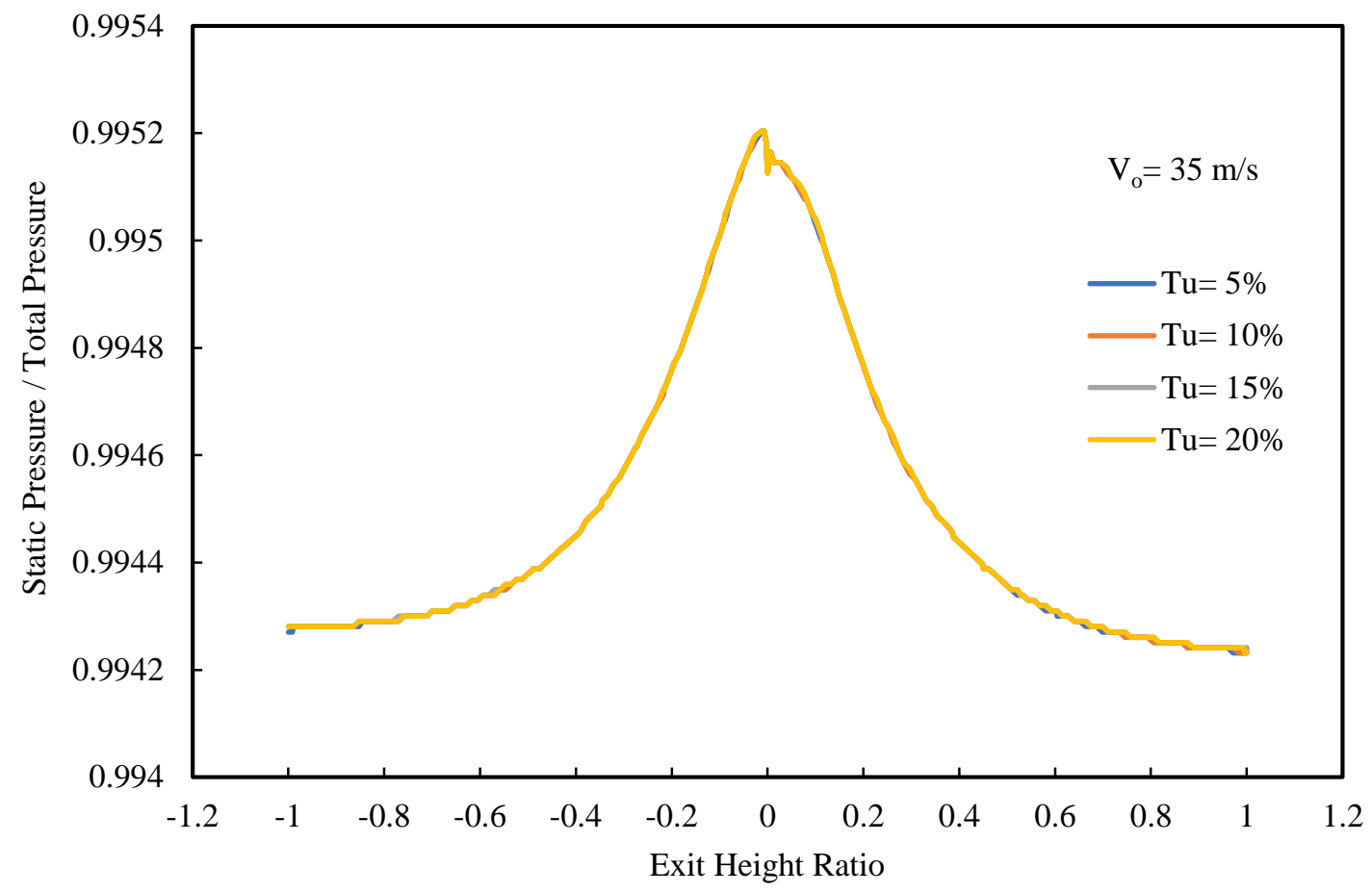

Fig. 21 Comparison of the pressure recovery on the dump diffuser with different inlet turbulence intensity.

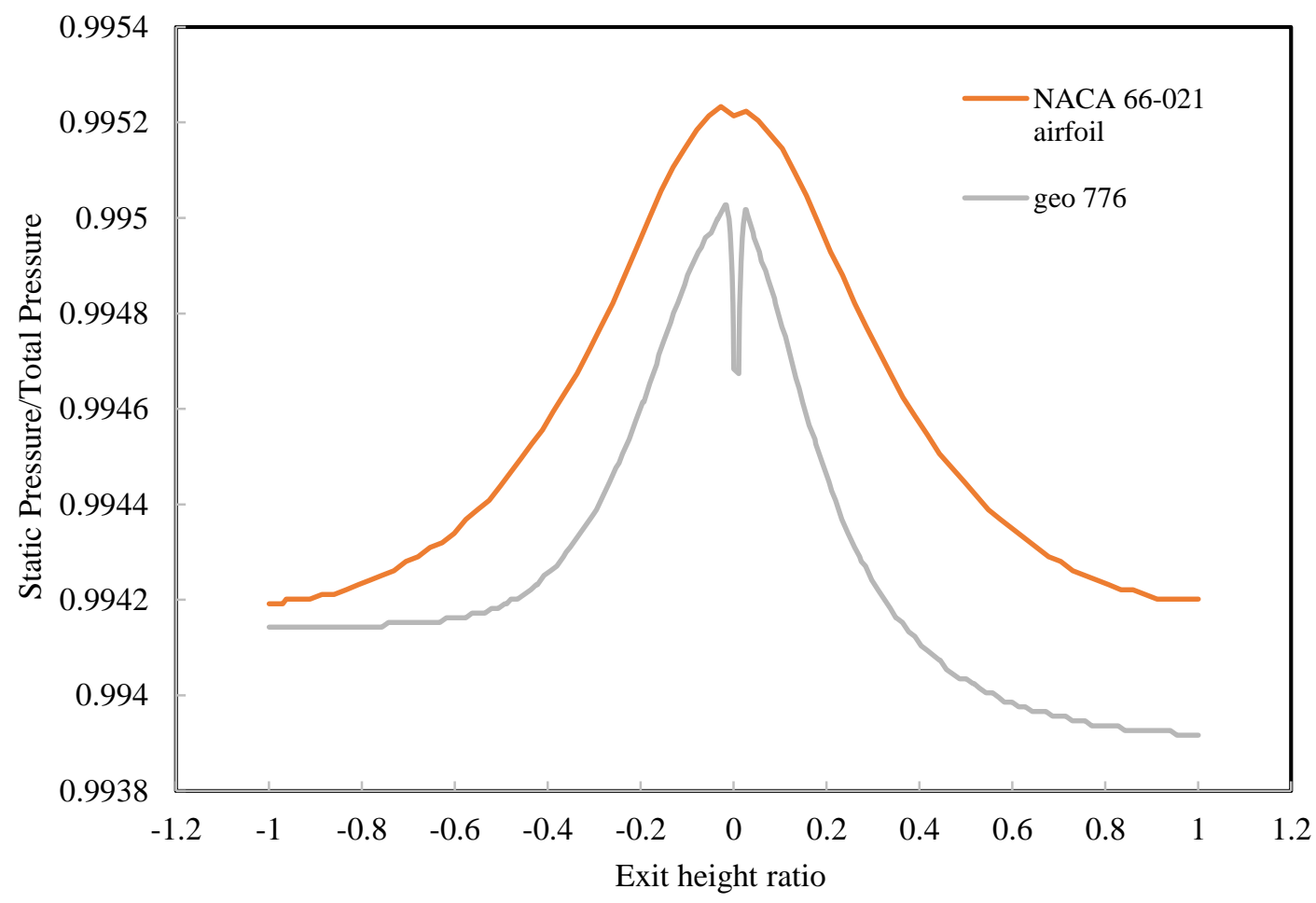

Fig. 22 Comparison of the static pressure recovery on the dump diffuser with airfoils Geo 776 and NACA 66-021. 


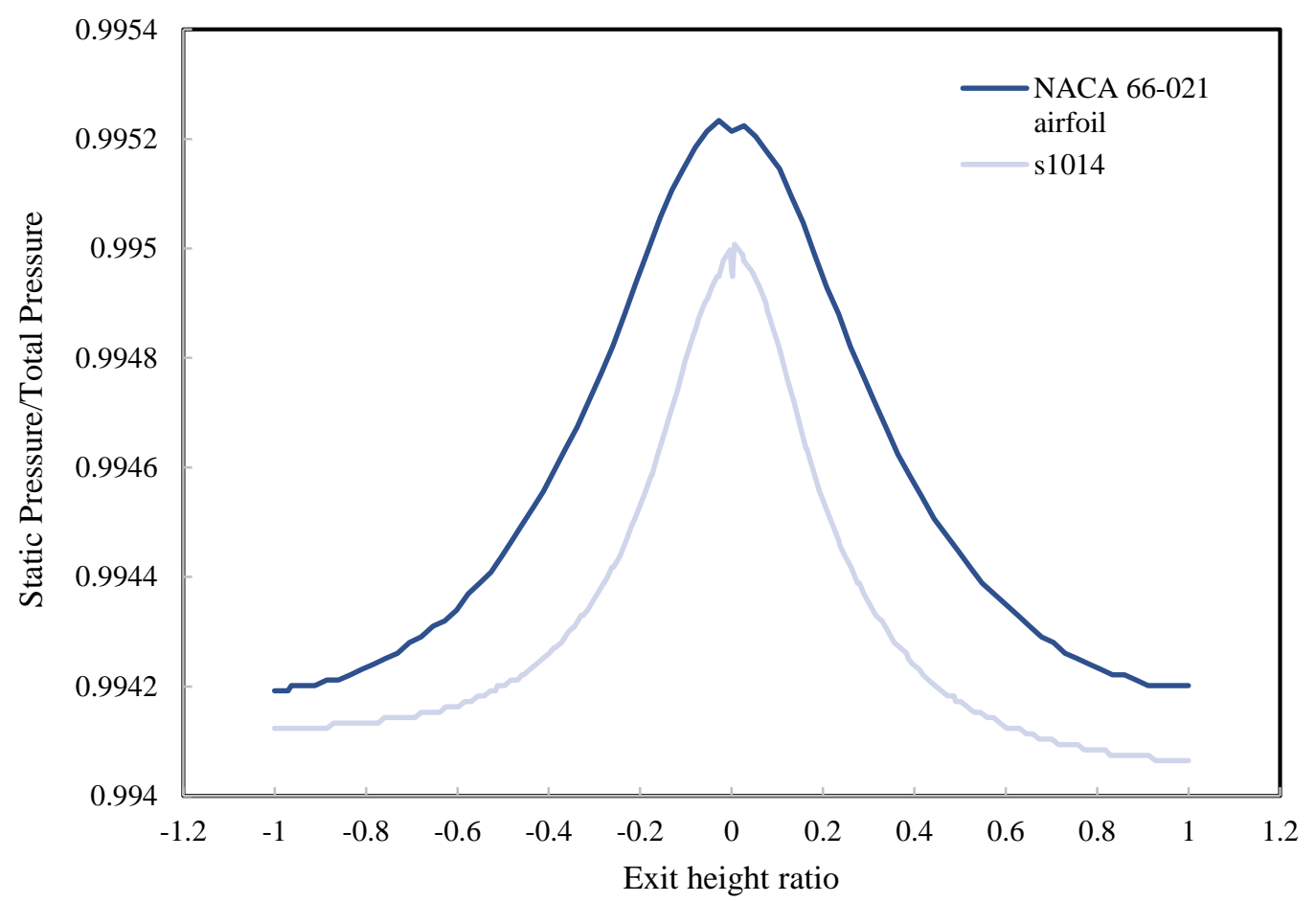

Fig. 23 Comparison of the static pressure recovery on the dump diffuser with airfoils NACA 66021 and $S 1014$.

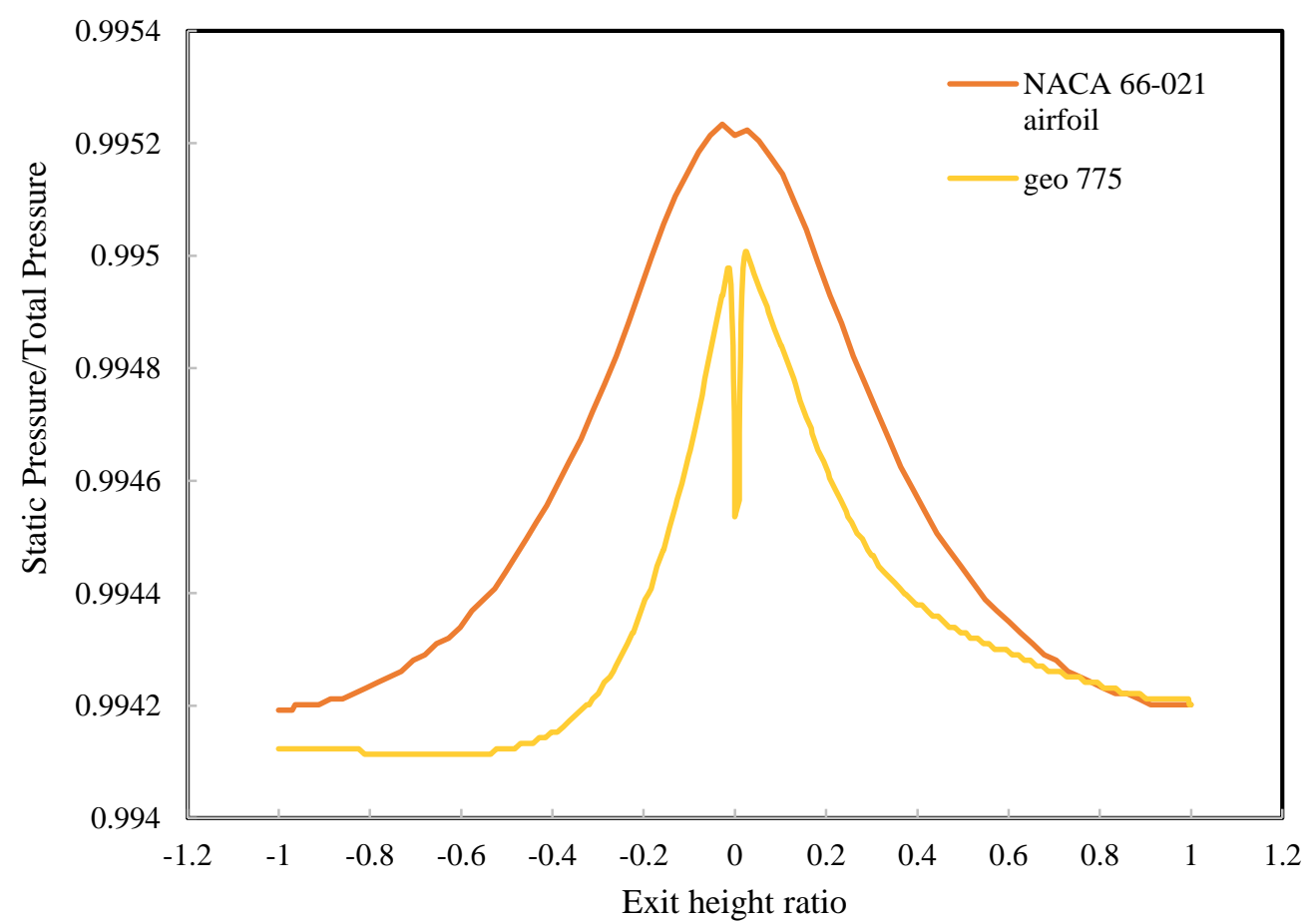

Fig. 24 Comparison of the static pressure recovery on the dump diffuser with airfoils NACA 66021 and Geo 775. 


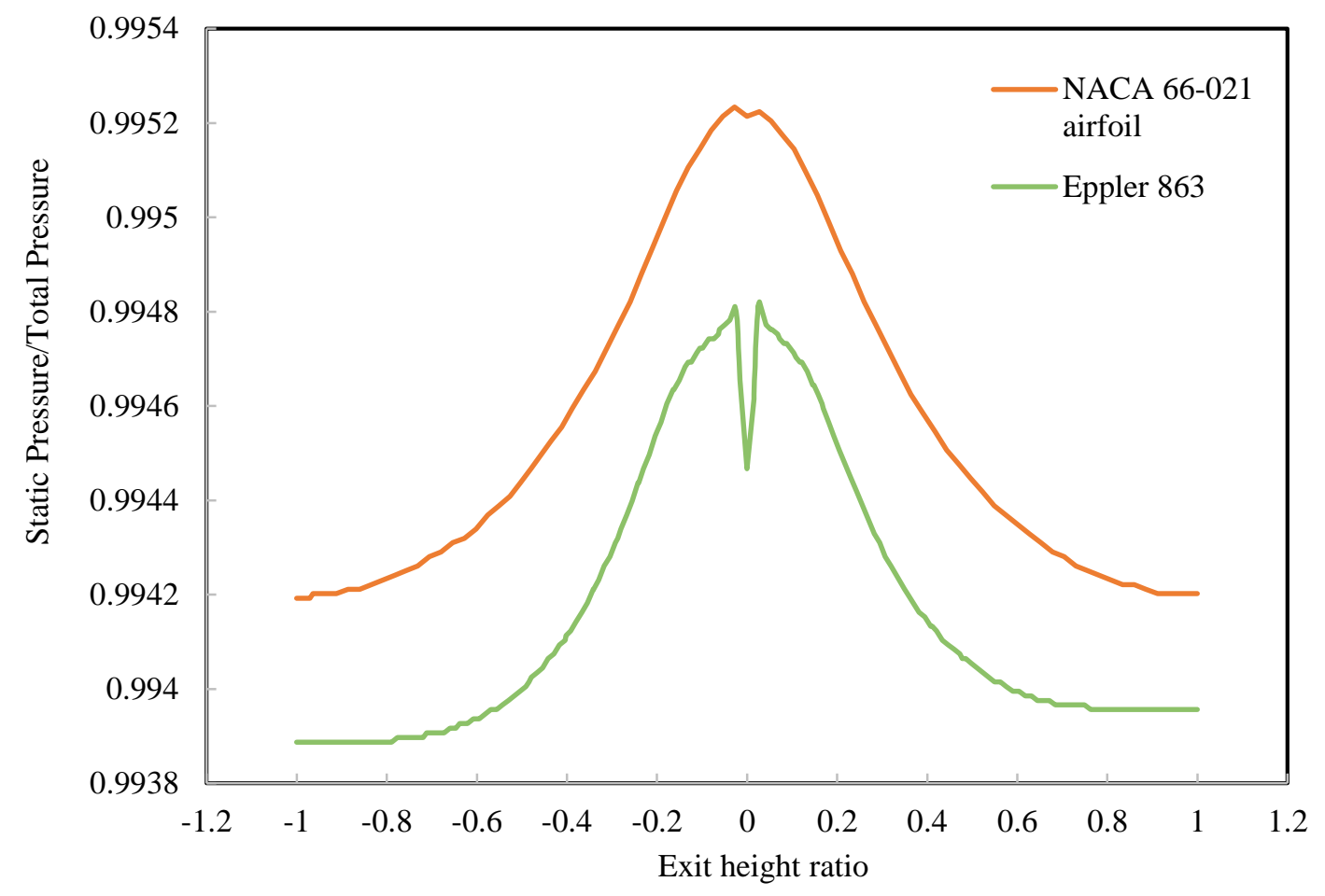

Fig. 25 Comparison of the static pressure recovery on the dump diffuser with airfoils NACA 66021 and Eppler 862.

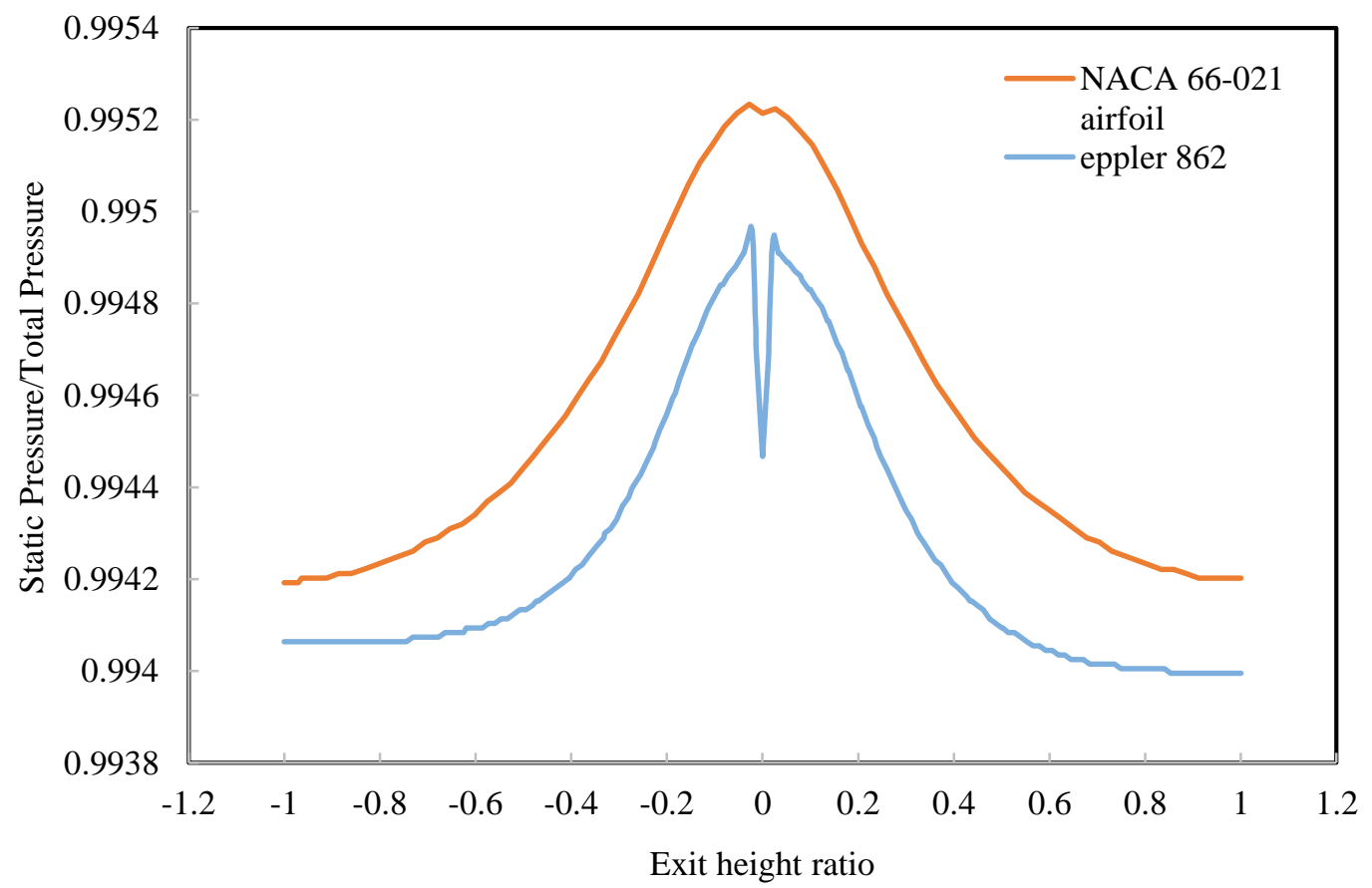

Fig. 26 Comparison of the static pressure recovery on the dump diffuser with airfoils NACA 66021 and Eppler 863. 
Table. 1 Investigated flame tube configurations on the dump diffuser.

\begin{tabular}{|c|c|c|c|}
\hline Case No. & Flame Tube Shape & Inlet Velocity $(\mathbf{m} / \mathbf{s})$ & $\left(\mathbf{P} / \mathbf{P}_{\mathbf{0}}\right)_{\max }$ \\
\hline Case 1 & NACA 66-021 & $\mathbf{3 0}$ & $\mathbf{0 . 9 9 5 3}$ \\
\hline Case 2 & NACA 16021 & 30 & 0.9952 \\
\hline Case 3 & NACA 0012 & 30 & 0.9950 \\
\hline Case 4 & NACA 4412 & 30 & 0.9946 \\
\hline Case 5 & NACA 65421 & 30 & 0.9947 \\
\hline Case 6 & NACA 0015 & 30 & 0.9944 \\
\hline Case 7 & NACA 0018 & 30 & 0.9945 \\
\hline Case 8 & NACA 0021 & 30 & 0.9946 \\
\hline Case 9 & NACA 0024 & 30 & 0.9948 \\
\hline Case 10 & NACA 16018 & 30 & 0.9947 \\
\hline Case 11 & NACA 63415 & 30 & 0.9946 \\
\hline Case 12 & EPPLER 473 & 30 & 0.9943 \\
\hline Case 13 & EPPLER 862 & 30 & 0.9948 \\
\hline Case 14 & EPPLER 863 & 30 & 0.9948 \\
\hline Case 15 & GEO 775 & 30 & 0.9949 \\
\hline Case 16 & GEO 776 & 30 & 0.9950 \\
\hline Case 17 & S 1014 & 30 & 0.9950 \\
\hline
\end{tabular}

\section{Concluding Remarks}

The main expected outcome for any dump diffuser design is to achieve complete combustion. From the detailed parametric studies carried out herein, we concluded that the thickness-to-chord $(\mathrm{t} / \mathrm{c})$ ratio of the flame tube is an important parameter, which needs to be optimized for achieving the highest pressure recovery. In addition to that, the angle ratio between the continuous divergent sections of the pre-diffuser region decides the flow path and its separation, which have a significant impact on achieving high static pressure recovery in the dump diffuser. We concluded that the static pressure recovery could be improved significantly by keeping an aerodynamically shaped flame tube. The fact is that such a flame tube is having an inherent high form drag and profile drag. Here we analyzed with symmetrical airfoils because the camber of an airfoil creates a flow distortion inside the dump diffuser section. Also, all the simulations conducted at a zero-degree angle of attack to avoid flow recirculation causing total pressure losses. From the analysis, we noticed that NACA 66-021 aerofoil provides maximum static pressure recovery at given operating conditions when compared with the other symmetrical aerofoils. Note that NACA 66-021 has a max thickness of $21 \%$ at $45 \%$ chord, which makes the flow to pass over the flame tube without losing its energy. We observed that NACA 16021 airfoil achieved pressure recovery closer to the NACA 66-021 airfoil with its max thickness of $21 \%$ at $50 \%$ chord. All these deliberations lead to conclude that the thickness to chord ratio $(\mathrm{t} / \mathrm{c})$ of an aerodynamically shaped flame tube has a significant effect on producing the high static pressure recovery for meeting the design objectives of a dump diffuser. We concluded that dump diffuser with multiple pre-diffuser cones and the adjustable aerodynamicallyshaped flame tube with its optimized thickness-to-chord ratio can provide the maximum pressure recovery to improve the combustion in a combustion chamber with the less number of compressor stages at different operating conditions.

\section{Acknowledgments}

The authors would like to thank the management of Kumaraguru College of Technology, Coimbatore - 641 049, Tamil Nadu, India for their extensive support of this research work.

\section{References}

[1] Aravind S, Sabarinathan G, Ajith Sukumaran, Amrith Mariappan, Sundararaj K, and V. R. Sanal Kumar. "Design of Pre-diffuser Cone for Dump Diffusers for Aero Gas Turbine Engines," The 2019 AIAA Propulsion and Energy Forum and Exposition, Indianapolis, Indiana, 19-21 August 2019, AIAA 2019-4258, https://doi.org/10.2514/6.2019-4258

[2] Aravind S, Sabarinathan G, Dhinakaran S, and Sanjay Kumar S, "Aerodynamics Design Optimization of Dump Diffusers with NACA 66-021 Shaped Flame Tube," Undergraduate Project Report, Dept. of Aeronautical Engineering, KCT, Coimbatore, India, June 2020.

[3] V.R. Sanal Kumar et al., Influence of dump gap on the performance characteristics of dump-diffusers, 16th international symposium on transport phenomena, ISTP-16, PRAGUE, 2005. 
[4] V.R. Sanal Kumar, Santhosh Kumar Sahoo, and S. Raghunathan., "Internal Flow Simulation of Dump Diffusers for Modern Aircraft Engines," 45th AIAA/ASME/SAE/ASEE Joint Propulsion Conference \& Exhibit, Colorado Convention Centre, Denver, CO, USA, 2-5 Aug 2009. doi: 10.2514/6.2009-4832.

[5] V. R. Sanal Kumar, Vigneshwaran Sankar, Nichith Chandrasekaran, and Sulthan Ariff Rahman M. "Modeling of Sanal Flow Choking Condition and Design Optimization of High-Performance Dual-thrust SRMs", AIAA Propulsion and Energy Forum, July 9-11, 2018, Cincinnati, Ohio, 2018 Joint Propulsion Conference, doi:10.2514/6.2018-4693.

[6] V R Sanalkumar, Abhijit Muraleedharan, Yasir Khan, A Arokkia Swamy and RMO Gemson, Studies on Dump Diffusers for Modern Aircraft Engines, 43rd AIAA/ASME/SAE/ASEE Joint Propulsion Conference \& Exhibit, 08 July 2007 - 11 July 2007 Cincinnati, OH, U.S.A, https://doi.org/10.2514/6.2007-5161

[7] Selvakarthick G, Ajith S, Hemasai N.D and V.R Sanal Kumar, "Parametrical Optimization of a three-dimensional Dump Diffuser with Aerodynamically-shaped Flame Tube for Modern Aircraft Engines" 52nd AIAA/SAE/ASEE Joint Propulsion Conference, AIAA 2016-5009. doi:10.2514/6.2016-5009.

[8] Klein, A., Characteristics of combustor diffuser, Progress in Aerospace Science, Vol. 31, pp. 171-271, 1995.

[9] Fishenden, C.R., and Stevens, S.J., "Performance of Annular Combustor-Dump diffuser," Journal of Aircraft, Vol. 14, pp.60-67, 1977.

[10] S. J. Stevens, U. S. L. Nayak, J. F. Preston. "Influence of Compressor Exit Conditions on Diffuser Performance". VOL. 15 , NO. 8.

[11] S.J. Stevens, A.P. Wray. "The Aerodynamic Performance of a Modern Vaporising Combustor Dump Diffuser". AIAA $-88-3273$.

[12] Ananda Reddy G, Ganesan V. "A numerical study of pre-diffuser optimization of an aero gas turbine combustion chamber", Indian Journal of Engineering \& Materials Sciences, 2005, 12(4): 281-291.

[13] Mongia H, Hsiao G, Burrus D, et al. Combustor Diffuser Modeling Part I: Inlet Profiles and 2-D Calculations. AIAA Paper, AIAA 2004-4168.

[14] Walker A D, Carrotte J F, Denman P A. Annular Diffusers with Large Downstream Blockage Effects for Gas Turbine Combustion Applications[J]. Journal of Propulsion and Power, 2011, 27(6): 1218-1231.

[15] A. H. Lefebvre, "The role of fuel preparation in low-emission combustion," Journal of Engineering for Gas Turbines and Power, vol. 117, no. 4, pp. 617-654, 1995. doi: 10.2514/3.23077.

[16] Ainley, D.G. (1945): "Investigations of Air Flow Through Some Annular Diffusers", Power Jet Report 1151.

[17] Johnston, I.H. (1953): "The Effect of Inlet Conditions on the Flow in Annular Diffusers", British Aeronautical Research Council, C.P. No. 178.

[18] Howard, J.H.G.; Thornton-Trump, A.B.; Henseler, H.J. (1967): "Performance and Flow Regimes for Annular Diffusers", ASME Paper 67-WA/FE-21.

[19] G. Sovran, and E.D. Klomp, "Experimentally determined optimum geometries for rectilinear diffusers with rectangular, conical or annular cross-section" Fluid Mechanics of Internal Flow, Sovran, G., (Editor), Elsevier, New York, 1967, pp $462-474$.

[20] Biaglow, J.A. (1971): "Effect of Various Diffuser Designs on the Performance of an Experimental Turbojet Combustor Insensitive to Radial Distortion of Inlet Air Flow", NASA TMX-2216

[21] Wagner, W.B.; Tanrikut, S.; Sokolowski, D.E. (1980): "Performance of Annular Predifuser-Combuster Systems", ASME Paper 80-GT-15. doi:10.1.1.826.9683.

[22] Japikse, D., 1984, “Turbo Machinery Diffuser Technology”, Concepts ETI.

[23] R. Srinivasan, W.G. Freeman, J. Grahmann, and Coleman, E., "Parametric evaluation of the Aerodynamic Performance of an Annular Combustor-Diffuser System," AIAA Paper 90-2163, 1990, doi:10.2514/6.1990-2163.

[24] Prakash Ghose, Amitava Datta, Achintya Mukhopadhyay, "Effect of Dome Shape on Static Pressure Recovery in the Dump Diffuser at Different Inlet Swirl, International Journal of Emerging Technology and Advanced Engineering, ICERTSD 2013, Feb 2013.ISSN 2250-2459.

[25] Shinji Honami, and T. Morioka, "Flow Behavior in a Dump Diffuser with Distorted Flow at the inlet," ASME Paper 90-GT-90, 1990.

[26] Leilei Xu, Yue Huang, Can Ruan, Peiyong Wangand Fei Xin, Study of the Dump Diffuser Optimization for Gas Turbine Combustors, APISAT2014”, 2014 Asia-Pacific International Symposium on Aerospace Technology, APISAT2014, Procedia Engineering 99 (2015) $828-834$

doi: 10.1016/j.proeng.2014.12.608

[27] R. Hestermann, S. Kim, A. Ben Khaled, and S. Wittig, Flow field and performance characteristics of combustor diffusers: A basic study, The American Society of Mechanical Engineers 345 E. 47th St., New York, N.Y. 10017, 94GT-212, Copyright (C) 1994 by ASME.

[28] Launder, B.E.; Spalding, D.B. (March 1974). "The numerical computation of turbulent flows". Computer Methods in Applied Mechanics and Engineering. 3 (2): 269-289. doi:10.1016/0045-7825(74)90029-2.

[29] V.R. Sanal Kumar et al., A closed-form analytical model for predicting 3D boundary layer displacement thickness for the validation of viscous flow solver, American Institute of Physics (AIP) Advances 8, 025315 (2018); doi: 10.1063/1.502033, View online: https://doi.org/10.1063/1.5020333.

[30] V.R. Sanal Kumar et al., "Sanal Flow Choking: A Paradigm Shift in Computational Fluid Dynamics Code Verification and Diagnosing Detonation and Hemorrhage in Real-World Fluid-Flow Systems," Advanced Science News, Global Challenges, May 2020, https://doi.org/10.1002/gch2.202000012

[31] Versteeg, Henk Kaarle, Malalasekera, Weeratunge (2007), "An introduction to Computational Fluid Dynamics", The Finite Volume Method. Pearson Education. 